
\title{
BResarch Soute \\ Improvement of Surface Quality based on Magnetorheological Fluids Flexible Fixture During Milling Thin-walled Parts
}

\section{Yong Zhang ( zy1140075575@163.com )}

University of Shanghai for Science and Technology

\section{Shan Gao}

Shanghai Aircraft Manufacturing Company Limited, China

\section{Ning Yang}

University of Shanghai for Science and Technology

\section{Xiaohui Jiang}

University of Shanghai for Science and Technology

\section{Guokuan Zhao}

Shanghai Aircraft Manufacturing Company Limited, China

Xiao Liu

Shanghai Aerospace Equipment Manufacturing Company Limited, China)

\section{Research Article}

Keywords: Thin-walled part, Magnetorheological flexible fixture, Milling, Processing parameters, Stiffness, Vibration, Machining quality, Flexible fixtures and fixture-workpiece system

Posted Date: June 15th, 2021

DOl: https://doi.org/10.21203/rs.3.rs-603290/v1

License: (c) (i) This work is licensed under a Creative Commons Attribution 4.0 International License. Read Full License 


\title{
Improvement of surface quality based on magnetorheological
}

\section{fluids flexible fixture during milling thin-walled parts}

\author{
Zhang Yong ${ }^{1}$, Gao Shan ${ }^{2}$, Yang Ning ${ }^{1}$, Jiang Xiaohui ${ }^{1}$, Zhao Guokuan ${ }^{2}$, \\ Liu Xiao ${ }^{3}$ \\ (1. College of Mechanical Engineering, University of Shanghai for Science \\ and Technology, Shanghai 200093, China \\ 2.Shanghai Aircraft Manufacturing Company Limited, China
}

3. Shanghai Aerospace Equipment Manufacturing Company Limited, China)

\begin{abstract}
Aerospace thin-walled parts have the characteristics of low stiffness and complex structure, which are easily deformed by machine tool vibration, cutting force and heat during machining. The traditional fixture is in point contact with the workpiece, and the workpiece bears uneven force, which results in poor surface quality and low precision of the part. Therefore, it is urgent to improve the machining efficiency and surface quality of workpiece. According to the performance of magnetorheological fluid, a magnetorheological flexible fixture is designed to completely wrap the parts so as to make them bear uniform force, improve the stiffness of the system and inhibit flutter. Firstly, the stiffness distribution of thin-walled parts, flexible fixtures and fixtureworkpiece system is studied in this paper. It can be seen that the symmetrical center stiffness of magnetorheological flexible fixtures is relatively low. Through milling experiments with single process parameters, it is found that when the rotational speed, cutting depth and feed speed change, the composite clamping effect is better than the traditional clamping effect, in which with the increase of rotational speed, the vibration acceleration in Ax, Ay and Az directions decreases by $25.16 \%, 26.87 \%$ and $10.78 \%$ respectively; When the cutting depth increases, Ay decreases by $23.12 \%$ at the maximum. When the feed speed changes, it decreases by $15.78 \%$. Finally, based on the case of milling thin-walled parts with magnetorheological flexible fixture, it is obtained that the coaxiality of composite clamped thin-walled parts decreases by $13.85 \%$, and the maximum decrease of cylindricity is $36.73 \%$. Roughness value Rz decreases by $80.47 \%$ at the maximum. In summary, the above results have verified that the machining quality of the magnetorheological flexible fixture is better.
\end{abstract}

Keywords: Thin-walled part; Magnetorheological flexible fixture; Milling; Processing parameters; Stiffness; Vibration; Machining quality; Flexible fixtures and fixtureworkpiece system

\section{Introduction}

Materials of aerospace thin-walled parts are difficult to machine. ${ }^{1}$ Because of cutting force, heat, machine tool vibration and other factors in the cutting process, coupled with its 
weak stiffness, complex shape and structure, the contact interface between the tool and the workpiece occurs uneven force and heat during milling the workpiece. Small rigid contact area and uneven force exist between traditional fixture and workpiece, which is prone to machining deformation, resulting in poor surface quality and low precision of the parts. At the same time, as part materials are removed, the geometric structure of the part evolves continuously, which makes the process system have time-varying dynamic characteristics. Therefore, the control of processing stability becomes a difficult problem.

With the development of sensing technology and intelligent materials, active intelligent clamping system has gradually become the research focus of scholars at home and abroad. ${ }^{2}$ Selvakumar et al. $^{3}$ proposed the dynamic response model of active fixture-thin-walled parts under dynamic load. $\mathrm{Li}$ et al. ${ }^{4}$ considered processing conditions fusion information model based on dynamic characteristics, and developed a flexible fixture that automatically responds to workpiece deformation during machining. Mohring et al. ${ }^{5}$ explained the influence with respect to processing performance and surface quality of thin-walled part through experimental and theoretical results. However, the traditional fixture is in point contact with the part, which leads to uneven stress, resulting in machining deformation.

At present, in the field of milling thin-walled parts, adjusting cutting process parameters is often used to enhance the stiffness of the process system. FEA software was used by Wang et $\mathrm{ll}^{6}$ and Jiang et al. ${ }^{7}$ to research the influence of machining parameters on redistribution of residual stress of workpiece by combining simulation and experiment. It is found that appropriately increasing cutting speeds ${ }^{8}$ and matching with smaller depth of cut can ensure milling efficiency and surface quality. Fekrmandi et al. ${ }^{9}$ found that tool geometric parameters have an important influence on milling chatter, and changing tool geometric parameters can improve stability by suppressing vibration. Ding et al. ${ }^{10,11,12}$ proposed different system stability methods to realize the stability of milling process through spindle variable speed cutting. Researchers revealed the effects of each parameter on the surface quality of workpiece by changing the parameters such as milling speed, feed rate, radial and axial depth in the machining process. The experimental results explain that the interaction between radial and axial depth has the most noticeable effect on surface quality. ${ }^{13}$ In the meantime, the method of the spindle speed controller to control the feed speed ${ }^{14}$ and the tool attitude optimization ${ }^{15,16}$ are also implemented to avoid the occurrence of milling chatter. However, in these methods, the machining quality of parts is easy to affect the adjustment of process parameters, and the process system composed of process stiffness enhancement methods does not have the characteristics of adjustable dynamic characteristics, thus causing great limitations.

The rheological properties of magnetorheological fluid can change continuously, rapidly and reversibly with the applied magnetic field. ${ }^{17,18}$ Solidification under the action of magnetic field can provide greater damping force that refers to shear stress. Based on this characteristic, Tang et al. ${ }^{19}$ designed a set of flexible fixture for magnetorheological fluid, which can provide a clamping force of about $80 \mathrm{kPa}$ under the influence of magnetic field. After pressurizing the writing wedge, the maximum clamping force is $800 \mathrm{MPa}$, which meets the processing requirements. Aydar et al. ${ }^{20}$ designed a magnetorheological fluid valve with permanent magnet and electromagnet control, which can output different damping forces according to actual working conditions. Mughni et al. ${ }^{21}$ proposed to analyze the performance 
of damper in shear-flow mixed mode from the effective region inside magnetorheological fluid material. The dynamic model of rotary MR damper is established by Imaduddin et al. ${ }^{22}$ Zhang et al. ${ }^{23}$ established a theoretical model of magnetorheological fluid shear stress and researched its relationship with workpiece position and magnetic field strength. Kim et al. ${ }^{24}$ considered a damping force model based on flow mode devices and calculated the corresponding model coefficients. Zhao et al. ${ }^{25}$ proposed the dynamic model of MR fixture clamping the workpiece to study the optimal parameters of MR fixture. Ma et al. ${ }^{26}$ established a flexible fixture based on the MR fluids to research the vibration suppression during milling the thin-walled part. Existing researches on magnetorheological fluids mostly focus on valve-type and shear-type devices in large amplitude and low frequency applications, while researches on small amplitude and high frequency vibration applications are less.

It is inevitable that vibration exists in the machining process of the workpiece. How to improve the system stiffness and suppress vibration so as to enhance the quality and milling accuracy of thin-walled parts needs to be solved urgently. Considering that magnetorheological fluid can completely wrap parts, overcome point contact, make workpieces bear uniform force and have better machining effect, this paper develops a magnetorheological flexible fixture suitable for thin-walled parts milling. First, fixtureworkpiece system, including magnetic field force model, pre-tightening model and milling force model, is analyzed. Then, the stiffness distribution of fixture-workpiece system is studied. Finally, its reliability is verified through milling comparative experiments.

\section{Magnetorheological flexible fixture-workpiece system}

The traditional fixture clamps parts, the contact surface between the workpiece and the machine tool is rigid contact, and the stress is uneven, which leads to local deformation of the part and makes it hard to ensure the surface quality. Therefore, this paper designs a new type of magnetorheological flexible fixture, whose clamping method is mechanical/magnetorheological composite clamping. Fig. 1 shows the schematic diagram of the device. The parts are uniformly stressed under the magnetorheological fluid package, and at the same time, under the action of mechanical pre-tightening force, the auxiliary support stiffness of the fixture is improved to make up for the deformation caused by uneven stiffness distribution of thin-walled parts caused by material removal. Under the action of magnetic field, the workpiece was subjected to three forces, the milling force $F_{1}$, magnetic field force $F_{i}$ and mechanical clamping force $F^{\prime}$.

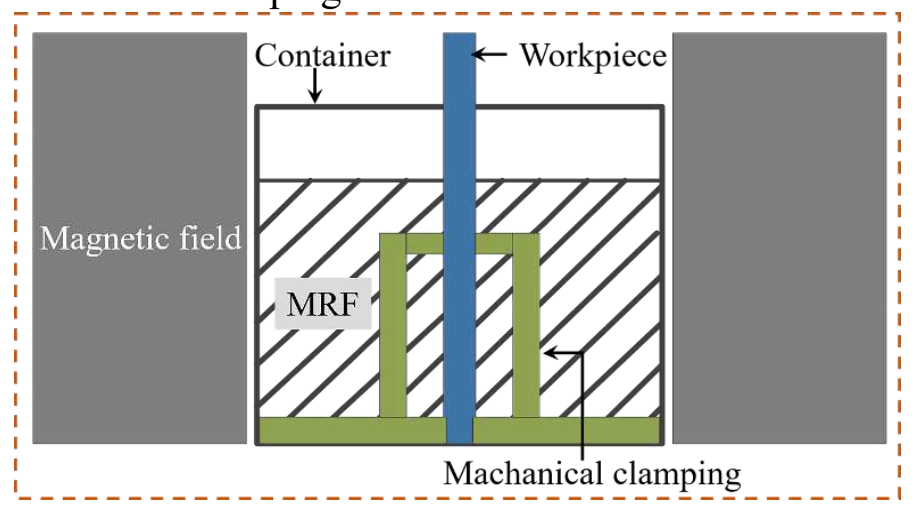

Fig. 1. The schematic diagram of magnetorheological flexible fixture. 


\subsection{Magnetic field force model}

The solid particles in magnetorheological fluid are uniform ferromagnetic particles. Assuming that the magnetic current region is $\Omega$, which composed of non-magnetic carrier liquid and $\mathrm{N}$ spherical ferromagnetic particles $\Omega_{1}, \Omega_{2}, \ldots, \Omega_{\mathrm{n}}$, Under the action of external static magnetic field, Maxwell's basic equations can be expressed ${ }^{25}$ :

$$
\nabla \times \mathbf{H}=\mathbf{J}, \quad \nabla . \mathbf{B}=0
$$

Among them, $\mathbf{J}$ is self-owned current, and the solution area considered has no selfowned current, so $\nabla \times \mathbf{H}=0$. Assuming that the material is isotropic, then:

$$
\mathbf{B}=\mu_{0}(\mathbf{H}+\mathbf{M})=\mu_{0}(1+\chi) \mathbf{H}=\mu_{0} \mu_{\mathrm{r}} \mathbf{H}=\mu \mathbf{H}
$$

Where, $\chi$ is the magnetic susceptibility and $\mu_{\mathrm{r}}=1+\chi$ is the relative magnetic permeability.

According to the scalar magnetic potential theory, the magnetic field strength can be expressed as:

$$
\mathbf{H}=-\nabla \varphi
$$

Combining the Eqs. (1) and (2), the following results are obtained:

$$
\nabla(\mu \nabla \varphi)=0
$$

$\mu$ can be determined by the magnetization characteristics of the material.

Given the initial conditions and boundary conditions, the scalar potential function $\varphi$ in Eq. (4) can be solved by using finite element software, thus obtaining the magnetic field distribution $\mathrm{H}$ of each node in the magnetorheological fluid region, and calculating Maxwell stress tensor by the following equation:

$$
\sigma^{\mathrm{N}}=\mu_{0}\left[H \mathrm{H}^{\mathrm{T}}-\frac{1}{2}|\mathrm{H}|^{2} \mathrm{I}\right]
$$

Therefore, the magnetic force received by the particle $\mathrm{i}$ in the magnetic field can be expressed as:

$$
\mathbf{F}_{\mathbf{i}}=\int_{\Omega_{\mathrm{k}}} \sigma^{\mathrm{N}} \cdot \mathbf{n} \mathrm{ds}=\int_{\Omega_{\mathrm{k}}} \mu_{0}\left[H H^{\mathrm{T}}-\frac{1}{2}|\mathrm{H}|^{2} \mathrm{I}\right] \cdot \mathbf{n d s}
$$

Where $\mathbf{I}$ is the second-order unit vector and $\mathbf{n}$ is the unit normal vector of the boundary $\Omega_{\mathrm{k}}$. The magnetic field force in Eq. (6) can be calculated by using Comsol magnetic field-free current module and the derived value of post-processing.

\subsection{Pre-tightening model}

According to the structure of the annular part to be processed, the V-shaped block and the pressing plate are designed to fix the workpiece, in which the V-shaped block and the bolt are matched to fix the lower half of the thin-walled part, and the two pressing plates are tightened by the bolts to fix and compact the upper half of the thinwalled part. Since the V-shaped block does not consider the influence on the processing of parts, the error caused by the positioning of the positioning block is ignored and only the bolt fixing effect is discussed. As shown in Fig. 2 (a), the bolt is balanced by the screw torque of the screw pair $T_{1}$ transmitted from the movable V-block under the action of the support surface torque $T_{2}$ and the clamping torque $T_{3}$ of the head.

$$
T_{1}=T_{2}+T_{3}
$$

In the equation, $T_{2}$ is the support surface, $\mathrm{N} \cdot \mathrm{m} ; T_{3}$ is the clamping moment, $\mathrm{N} \cdot \mathrm{m}$. 
Therefore, the bolt is twisted, and the torque is expressed in Fig. 2 (b). The thread torque is generated by the inclined plane and friction of the thread pair. Under its influence, the thread pair has the effect of circumferential force $F_{t}$. At this time, the bolt is subjected to axial tension $F^{\prime}$, as shown in Fig. 2 (a), so that the movable V-shaped block and the fixed V-shaped block clamp the thin-walled piece.

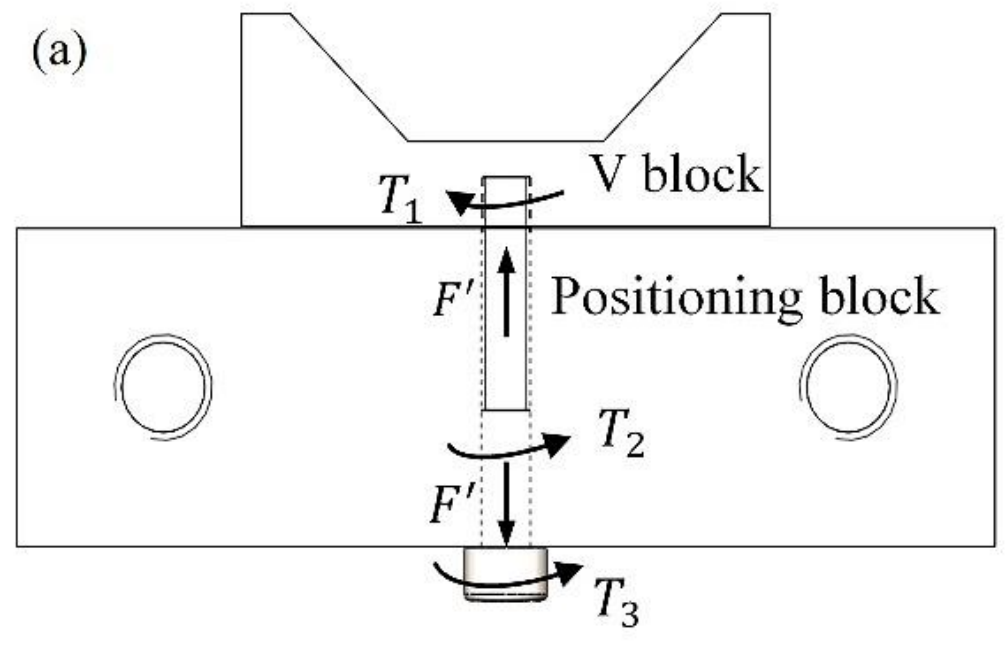

(b)

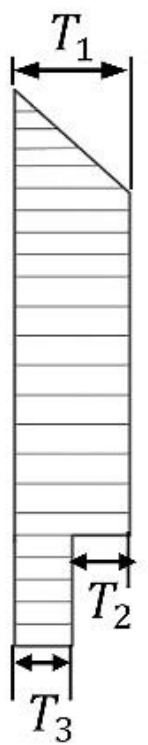

Fig. 2. Stress of bolts and V-shaped blocks when fixing thin-walled parts. (a) top view; (b) torque of the bolt.

The relationship between the thread torque and the circumferential force of the thread pair can be shown as follows:

$$
\begin{aligned}
T_{1}= & \frac{F_{t} d_{2}}{2} \\
& =F^{\prime} \tan \left(\lambda+\xi^{\prime}\right) \cdot d_{2} / 2
\end{aligned}
$$

Where, $F_{t}$ is a circular force, $\mathrm{N} ; d_{2}$ is the thread diameter, $\mathrm{mm} ; F^{\prime}$ is the axial tensile force on the bolt, $\mathrm{N} ; \xi^{\prime}$ is the equivalent friction angle of the thread pair, ${ }^{\circ} ; \lambda$ is the screw lift angle, ${ }^{\circ}$.

The torsional shear stress $\tau$ of the bolt is:

$$
\begin{aligned}
\tau & =\frac{T_{1}}{\frac{\pi d_{c}^{3}}{16}} \\
& =\frac{F^{\prime} \tan \left(\lambda+\xi^{\prime}\right) \frac{d_{2}}{2}}{\frac{\pi d_{c}^{3}}{16}}
\end{aligned}
$$

In Eq. (9), $d_{c}$ is the diameter of the dangerous cross-sectional area of the thread, mm; $\tau$ is torsional shear stress, $\mathrm{N} / \mathrm{mm}^{2}$.

Therefore, Eq. (9) can be changed to:

$$
F^{\prime}=\frac{\pi d_{c}^{3}}{8 \tan \left(\lambda+\xi^{\prime}\right) d_{2}} \cdot \tau
$$

Among them, $\xi^{\prime}$ depending on the friction coefficient $\mu$ and thread shape, in ordinary triangular threads: 


$$
\xi^{\prime}=\arctan (\mu / \cos \beta)
$$

In Eq. (11), $\mu$ is the friction coefficient of the thread pair, and $\beta$ is the thread profile angle. The spiral lift angle of the thread $\lambda$ is expressed as:

$$
\lambda=\arctan \left(P / \pi d_{2}\right)
$$

Which $P$ is the pitch of the thread. For common triangular threads:

$$
d_{2}=d-0.6495 P
$$

which $\mathrm{d}$ is the nominal diameter of the thread.

The equation for calculating the dangerous broken cross-sectional area of threads $A_{3}$ is as follows:

$$
A_{3}=\frac{\pi}{4}\left(\frac{d_{2}+d_{3}}{2}\right)^{2}
$$

Therefore:

$$
d_{c}=\left(d_{2}+d_{3}\right) / 2
$$

$\mathrm{d}_{3}=\mathrm{d}_{1}-0.866 \mathrm{P} / 6, \mathrm{~d}_{1}=\mathrm{d}-1.0825 \mathrm{P}$, where $\mathrm{d}_{1}$ is the thread diameter, $\mathrm{d}_{3}$ is calculated diameter of thread. The Eq. (15) is simplified to obtain:

$$
d_{c}=d-0.9381 P
$$

The $\xi^{\prime}$ and $\lambda$ in Eqs. (11) and (12) is very small, so:

$$
\tan \left(\lambda+\xi^{\prime}\right) \approx \tan \lambda+\tan \xi^{\prime}
$$

Substituting Eqs. (11) and (12) into Eq. (17) results in:

$$
\tan \lambda+\tan \xi^{\prime}=\frac{P}{\pi d_{2}}+1.155 \mu
$$

Substituting Eq. (18) into (10) to obtain the axial tensile force on the bolt $\mathrm{F}^{\prime}$ :

$$
\begin{aligned}
& F^{\prime}= \frac{\pi d_{c}^{3}}{8 \tan \left(\lambda+\xi^{\prime}\right) d_{2}} \cdot \tau \\
&=\frac{\pi d_{c}^{3}}{8\left(\mathrm{P} / \pi d_{2}+1.155 \mu\right) d_{2}} \cdot \tau
\end{aligned}
$$

In addition to the positioning and clamping of the $\mathrm{V}$-shaped block and the bolt, the thinwalled piece is also fixed by the two pressure plates to prevent the workpiece from sliding in the vertical direction, as shown in Fig. 3. Among them, the two pressure plates are each provided with a threaded hole and a through groove, and the threaded hole is used for vertically moving and positioning the bolt in the Y direction, as expressed in Fig. 3 (a); The through groove can be adjusted to move horizontally in the $\mathrm{X}$ direction according to the shape of the workpiece, as shown in Fig. 3 (b), so as to achieve flexible positioning; Both bolts are connected to the threaded holes at the bottom of the container.
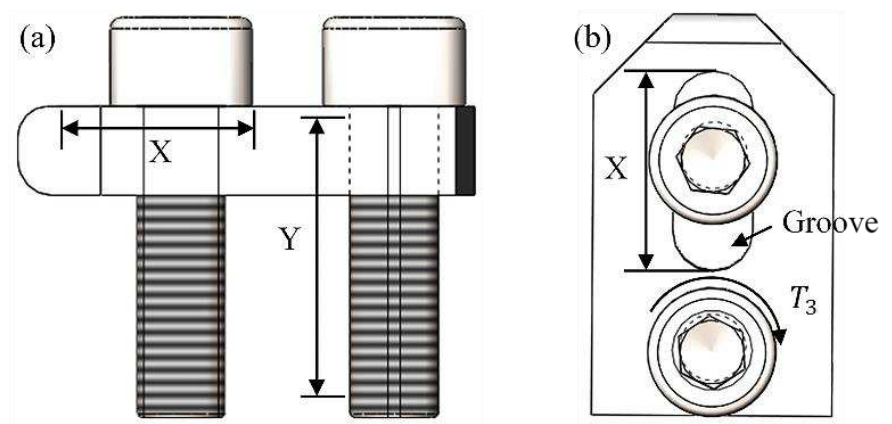

Fig. 3. Fixing of pressing plate. (a) front view; (b) top view.

In this study, aerospace rotary parts are taken as the processing and clamping objects, and their received force is analyzed, as shown in Fig. 4. Since the bolts at the 
groove have no acting force and only play a positioning effect, the workpiece is subjected to the vertical downward pressure of the two pressure plates $2 \mathrm{~F}^{\prime}$ and the reaction force $2 \mathrm{~F}^{\prime \prime}$ at the bottom of the container. At the same time, the left and right $\mathrm{V}$-shaped blocks have a pair of forces with opposite directions and equal sizes on the parts $\mathrm{F}^{\prime}$, and the workpiece of $\mathrm{F}^{\prime \prime}$ is balanced in force.

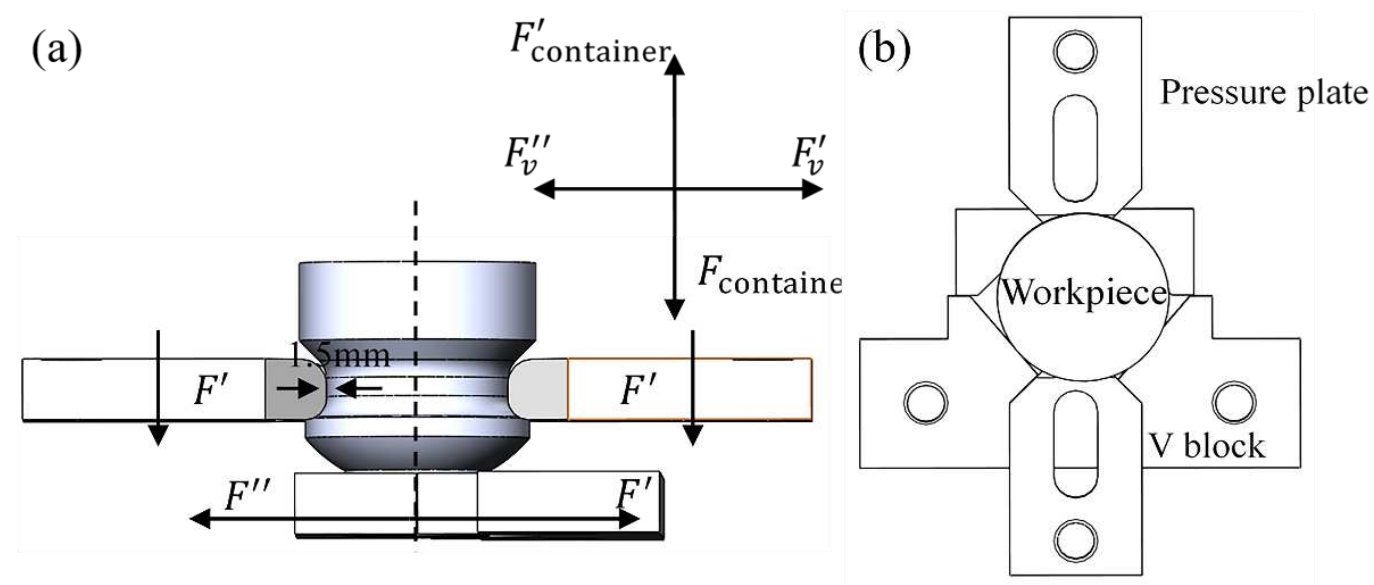

Fig. 4. Mechanical clamping and fixing. (a) front view; (b) top view.

\subsection{Milling force model}

In the machining process, the workpiece material resists the cutting force generated by the cutter. The magnitude of milling force is affected by process parameters, and the equation of milling force ${ }^{27}$ is shown as follows:

$$
\mathrm{F}_{1}=\mathrm{C}_{\mathrm{p}} \times \mathrm{a}_{\mathrm{p}}^{\mathrm{x} 1} \times \mathrm{f}_{\mathrm{z}}^{\mathrm{x} 2} \times \mathrm{D}^{\mathrm{x} 3} \times \mathrm{B}^{\mathrm{x} 4} \times \mathrm{z} \times \mathrm{K}_{\mathrm{p}}
$$

Among them, $\mathrm{C}_{\mathrm{p}}$ is the coefficient with regard to the workpiece material and milling cutter type, $a_{p}$ represents the milling depth, $f_{z}$ shows the feed per tooth, the milling cutter diameter is $\mathrm{D}, \mathrm{B}$ is the milling width, $\mathrm{z}$ is the number of milling cutter teeth, and $\mathrm{K}_{\mathrm{p}}$ is the correction coefficient considering the mechanical properties of the workpiece material.

\section{Research on stiffness distribution of magnetorheological flexible}

\section{fixture}

The vibration problem is easy to occur in machining the workpiece. The main reason is that the stiffness of its machining process system cannot meet the needs of actual milling. In order to meet the actual machining requirements, this paper uses magnetorheological flexible fixture to support thin-walled parts to improve their local stiffness, and uses the magnetostrictive characteristics of magnetorheological fluid to absorb vibration energy, so as to convert the vibration energy generated by milling into other forms of storage or dissipation, thus inhibiting machining vibration and improving machining quality.

\subsection{Research on stiffness distribution of thin-walled parts}

The machining accuracy of thin-walled parts is closely related to the stiffness of the point contact between the workpiece and the machine tool during milling the thinwalled part, so it is very important to study the stiffness distribution law of thin-walled 
parts. Assuming that the contact point between the fixture-workpiece and the cutter is $\mathrm{Q}(\mathrm{x}, \mathrm{y}, \mathrm{z})$ and the deformation amount is $\triangle \mathrm{Q}(\mathrm{x}, \mathrm{y}, \mathrm{z})$, the stiffness value of this point is $\mathrm{K}(\mathrm{x}, \mathrm{y}, \mathrm{z})$, and the milling force $\mathrm{F}_{1}(\mathrm{x}, \mathrm{y}, \mathrm{z})$ is applied to this point, the stiffness value of this point can be expressed by Eq. (21):

$$
K(x, y, z)=\frac{F_{1}(x, y, z)}{\Delta Q(x, y, z)}
$$

The deformation amount at this point is determined by the stiffness of the magnetorheological fluid fixture and the workpiece. Assuming that the stiffness of the workpiece is $\mathrm{K} 1(\mathrm{x}, \mathrm{y}, \mathrm{z})$, the stiffness of the magnetorheological flexible fixture is $\mathrm{K} 2(\mathrm{x}, \mathrm{y}, \mathrm{z})$, and the respective forces are $\mathrm{F}_{\mathrm{k} 1}$ and $\mathrm{F}_{\mathrm{k} 2}$ respectively, the deformation amount at this point can be expressed as Eq. (22):

$$
\triangle \mathrm{Q}(\mathrm{x}, \mathrm{y}, \mathrm{z})=\frac{\mathrm{F}_{\mathrm{k} 1}}{\mathrm{~K} 1(\mathrm{x}, \mathrm{y}, \mathrm{z})}+\frac{\mathrm{F}_{\mathrm{k} 2}}{\mathrm{~K} 2(\mathrm{x}, \mathrm{y}, \mathrm{z})}
$$

In Eq. (22), the greater the stiffness value of the contact point, the smaller the relative displacement of the point and the stronger the system's ability to resist external excitation. Using magnetorheological flexible fixture can effectively increase the stiffness of fixture-workpiece.

In the experiment, frame type aluminum alloy thin-walled part is selected and three-dimensional diagram is shown in Fig. 5.

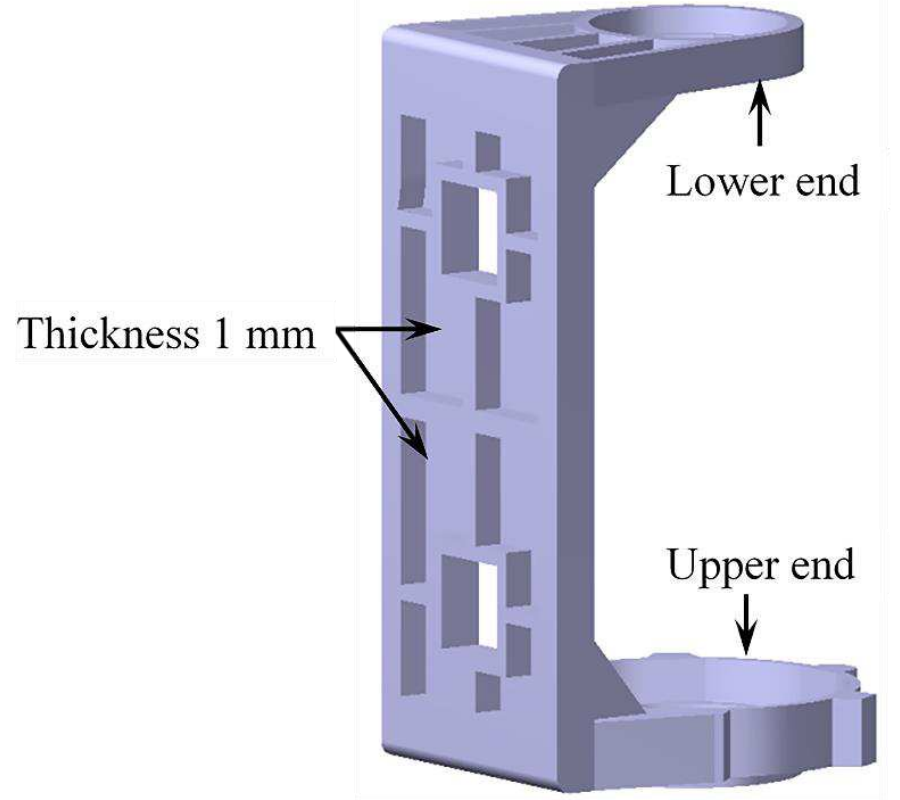

Fig. 5. Diagram of frame type aluminum alloy thin-walled part.

The upper end is large and complex, the lower end is small. On the side of the thinwalled part existing many grooves, and the wall thickness is $1 \mathrm{~mm}$. The experimental equipment is non-contact vibration measuring equipment, laser vibration measuring instrument (PSV-400) composed of three parts: vibration measurement system, data acquisition and computer. Modal impact hammer (PCB 086C04) was used to hammer the selected six testing points of aerospace thin-walled parts, as exhibited in Fig. 6. 

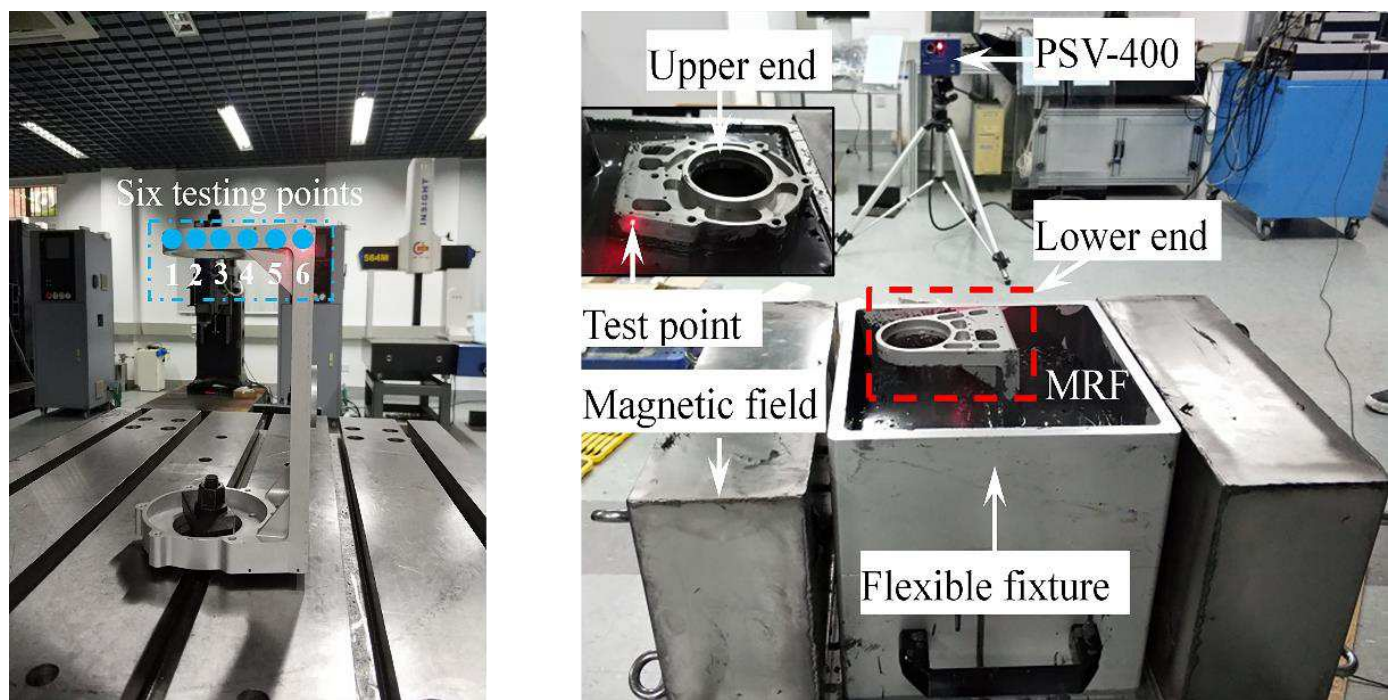

Fig. 6 Stiffness test of thin-walled parts Fig. 7 Stiffness test of flexible fixture.

\subsection{Research on stiffness distribution of flexible fixture system}

The stiffness of the magnetorheological flexible fixture mainly comes from the magnetorheological fluid. Dipole theory knows that the magnetic particles in the magnetorheological fluid are arranged in chains in the magnetic field, while the vibration of the milling workpiece leads to a weak change in the position of the surrounding magnetorheological fluid, which makes the chain of magnetic particles in the magnetic field unbalanced and the magnetic particles will be rearranged. This process is simplified as a compression spring, and the elastic coefficient of the spring is unknown. The stiffness value $\mathrm{k}$ of the simplified magnetorheological flexible fixture system can be calculated from the magnetic field force $F_{11}$ at the end equilibrium position of the starting spring and the final equilibrium position $\mathrm{F}_{12}$, as well as the deformation amount $\mathrm{X}$.

The work $\mathrm{W}$ done by the magnetic field force generated by the magnetic field action of the magnetorheological flexible fixture in one vibration period of the workpiece is:

$$
\mathrm{W}=\int_{0}^{\mathrm{T}} \mathrm{kxdx}=\frac{\mathrm{F}_{11}+\mathrm{F}_{12}}{2} \mathrm{X}
$$

\subsection{Research on stiffness distribution of fixture-workpiece system}

For researching the enhancement effect of magnetorheological flexible fixture on the stiffness of the weak part of thin-walled parts, the vibration displacement of a node in the weak part of thin-walled parts is measured, and the point stiffness of workpiecefixture coupling is calculated, so as to compare with the point stiffness of the weak part without magnetorheological flexible fixture. Place the workpiece to be tested in a magnetorheological flexible fixture, change the position of the workpiece in the container, inject different volumes of magnetorheological and test, and the field test is shown in Fig. 7.

\section{Milling experiment based on magnetorheological flexible fixture}

\subsection{Milling experiment with single process parameters}

Selecting the optimal process parameters is the key factor to ensure the milling efficiency and surface quality of thin-walled part. Section 4.1 changes the spindle 
speed, feed rate and milling depth respectively to explore the effects of milling parameters on the vibration during milling with or without magnetorheological fluid clamping mode. The single process parameter is shown in Table 1.

Table 1. Experimental test scheme for single factor process parameters

\begin{tabular}{cccc}
\hline No & $\begin{array}{r}\text { Spindle speed } \\
(\mathrm{r} / \mathrm{min})\end{array}$ & $\begin{array}{c}\text { Cutting depth } \\
(\mathrm{mm})\end{array}$ & $\begin{array}{c}\text { Feed rate } \\
(\mathrm{mm} / \mathrm{min})\end{array}$ \\
\hline 1 & 8000 & 0.1 & 300 \\
2 & 10000 & 0.2 & 400 \\
3 & 12000 & 0.3 & 500 \\
4 & 14000 & 0.4 & 600 \\
\hline
\end{tabular}

Experimental equipment: machine tool (JD Carver S600B-RT) and acceleration sensor (Kistler 8763B100BB). $\emptyset 6 \mathrm{~mm}$ hard alloy flat-bottom milling cutter and aluminum alloy (7050) annular parts are selected, and the experiments are shown in Fig. 8 (a) and (b). Under the same processing number, with or without magnetorheological fluid clamping, the tool path is $10 \mathrm{~mm}$.
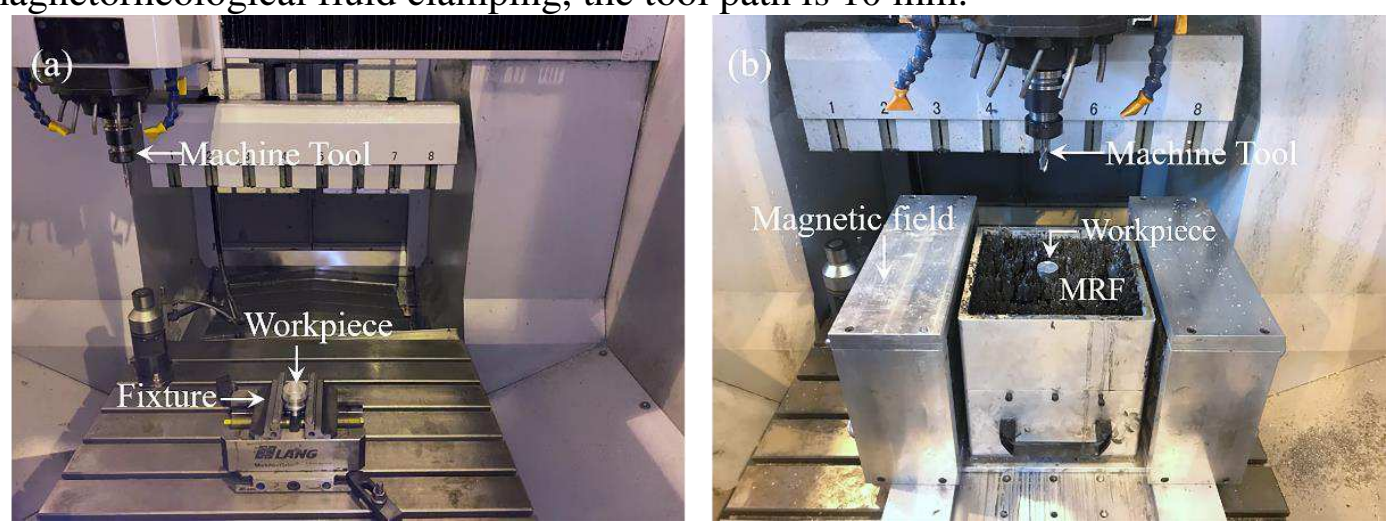

Fig. 8. Experimental machining. (a) mechanical clamping; (b) magnetorheological clamping.

\subsection{Milling case of magnetorheological flexible fixture}

Experimental steps: After turning the outer circle of aluminum alloy (7050), $\emptyset 4 \mathrm{~mm}$ hard alloy flat-bottomed milling cutter and vice were used to rough mil the $\emptyset 26 \mathrm{~mm}$ inner hole with a margin of $1 \mathrm{~mm}$. The machining parameters were: rotational speed $10000 \mathrm{r} / \mathrm{min}$, feed speed $400 \mathrm{~mm} / \mathrm{min}$, cutting depth $0.4 \mathrm{~mm}$ and processing depth $17 \mathrm{~mm}$; Then, the magnetorheological flexible fixture is used to finish the remaining amount of the inner hole. The cutting tools are the same. The processing parameters are: rotational speed $10000 \mathrm{r} / \mathrm{min}$, feeding speed $300 \mathrm{~mm} / \mathrm{min}$, cutting depth $0.3 \mathrm{~mm}$ and processing depth $17 \mathrm{~mm}$. The processing site is shown in Fig. 8.

\section{Results and discussions}

\subsection{Stiffness distribution analysis of thin-walled parts}

As shown in Fig. 9, the data measured through experiments are drawn. The impact force is $18 \mathrm{~N}$, the upper surface stiffness value of frame-like thin-walled parts is relatively large, the deformation is small during milling, and the stiffness is minimum when the edge with small thickness is raised. Therefore, during milling, auxiliary support should be added to the parts with weak wall thickness or cantilever. 


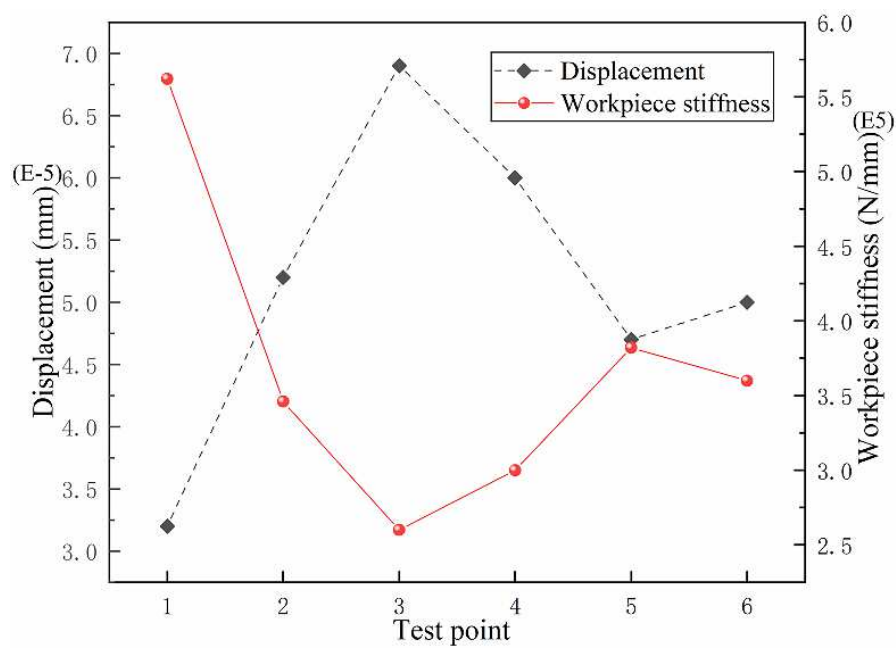

Fig. 9. Test results of workpiece point stiffness.

\subsection{Analysis of stiffness distribution of flexible fixture system}

When $4 \mathrm{~L}$ magnetorheological fluid is injected, the simulated magnetic field force and calculated stiffness are shown in Table 2. Eight test points are selected for stiffness testing of the workpiece, as shown in Fig. 10. From Table 2, it is found that the stiffness of the magnetorheological flexible fixture is different at different positions, among which the stiffness value of the symmetrical center is the lowest and presents a Ushaped distribution. It can be seen that the phase change suppression vibration of the magnetorheological fluid is mainly used to reduce the resultant force of the magnetorheological fixture-workpiece system through the reverse magnetic field force, absorb the energy of workpiece vibration, and store it in the magnetorheological fluid.

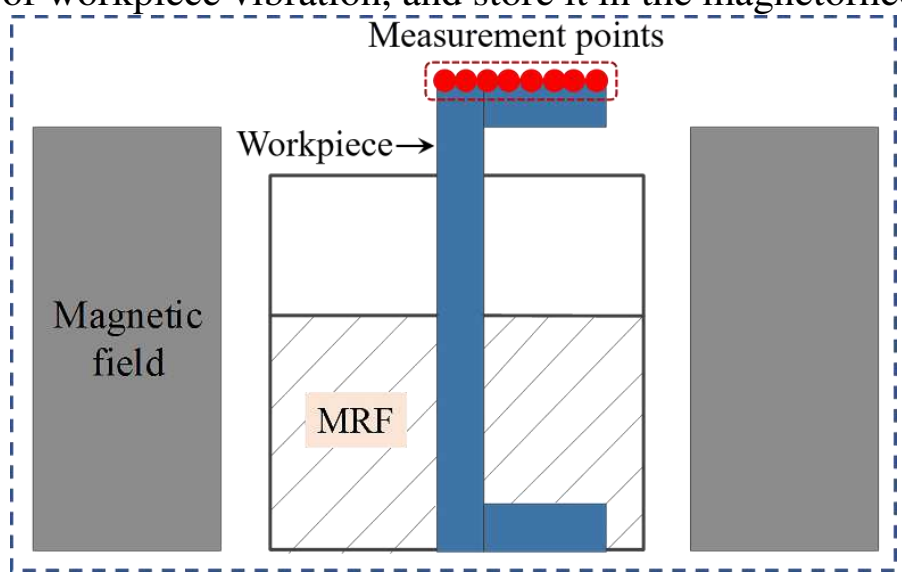

Fig. 10 Diagram of test points positions.

Table 2. Calculation of fixture stiffness

X-direction

Position (mm) magnetic field force

(N)
Y-direction magnetic

field force $(\mathrm{N})$
Stiffness $(\mathrm{N} / \mathrm{m})$

\begin{tabular}{cccc}
\hline 100 & 223.84 & 22.425 & 0 \\
99 & 218.58 & 27.034 & 5260 \\
98 & 217.89 & 30.477 & 690 \\
97 & 219.95 & 23.784 & 2140
\end{tabular}




\begin{tabular}{llcc}
96 & 217.77 & 32.072 & 2180 \\
95 & 219.15 & 33.04 & 2620 \\
94 & 217.86 & 24.459 & 1090 \\
93 & 217.33 & 31.508 & 530 \\
\hline
\end{tabular}

\subsection{Stiffness distribution analysis of fixture-workpiece system}

Table 3 shows that the stiffness of the workpiece at the same position is about 2-6 times of the original when the magnetorheological flexible fixture is clamped compared with the workpiece without magnetorheological clamping. At the same time, the magnetorheological fluid fills half of the workpiece height to the whole workpiece height, and the workpiece stiffness does not change obviously. When the magnetorheological fluid covers the whole workpiece, the workpiece stiffness increases significantly. The magnetorheological fluid undergoes phase change under the influence of strong magnetic field and is completely attached to the outer surface of the workpiece. Therefore, the height of the workpiece wrapped by the magnetorheological fluid is equivalent to that of the workpiece being fixed. Only the workpiece above the magnetorheological fluid can vibrate. Therefore, the positioning depth in the clamping parameters should be reasonably considered when using the magnetorheological flexible fixture.

According to the stiffness of magnetorheological fluid itself, its stiffness is far less than that of the workpiece. Dipole theory explains that magnetorheological fluid is equivalent to the combination of countless springs, which mainly reduces the resultant force on the workpiece, absorbs the energy excited by the outside world, suppresses the vibration, and reduces the amplitude of the vibration of the workpiece.

Table 3. Calculation of coupling stiffness of magnetorheological flexible fixture

\begin{tabular}{cccc}
\hline Experiment number & $\begin{array}{c}\text { height h } \\
(\mathrm{mm})\end{array}$ & $\begin{array}{c}\text { Y-direction } \\
\text { displacement }(\mathrm{um})\end{array}$ & $\begin{array}{c}\text { stiffness } \\
(\mathrm{N} / \mathrm{m})\end{array}$ \\
\hline 1 & 0 & 39.6 & $6.06 \times 10^{5}$ \\
2 & 100 & 17.3 & $1.84 \times 10^{6}$ \\
3 & 125 & 28.4 & $1.12 \times 10^{6}$ \\
4 & 150 & 20.4 & $1.56 \times 10^{6}$ \\
5 & 175 & 14.9 & $2.14 \times 10^{6}$ \\
6 & 200 & 18.2 & $1.75 \times 10^{6}$ \\
7 & 225 & 24.1 & $3.98 \times 10^{6}$ \\
\hline
\end{tabular}

\subsection{Analysis of milling results with single process parameters}

(1). Influence of spindle speed on workpiece vibration

As shown in Fig. 11, with or without MRF clamping the workpiece, the maximum acceleration in Ax, Ay and Az directions at 8000 (r/min), 10000 (r/min), 12000 (r/min) 
and $14000(\mathrm{r} / \mathrm{min})$ spindle speeds is shown. As can be seen from the figure, the spindle speed increases, the acceleration will decrease slightly, but the amplitude is very small, which shows that the spindle speed is not the main factor affecting the vibration acceleration. For improving the milling quality, the spindle speed of finishing can be appropriately increased to reduce the vibration acceleration. The vibration with MRF clamping mode is less than that without MRF clamping, Az, Ay and Ax decrease by $10.78 \%, 26.87 \%$ and $25.16 \%$ respectively.

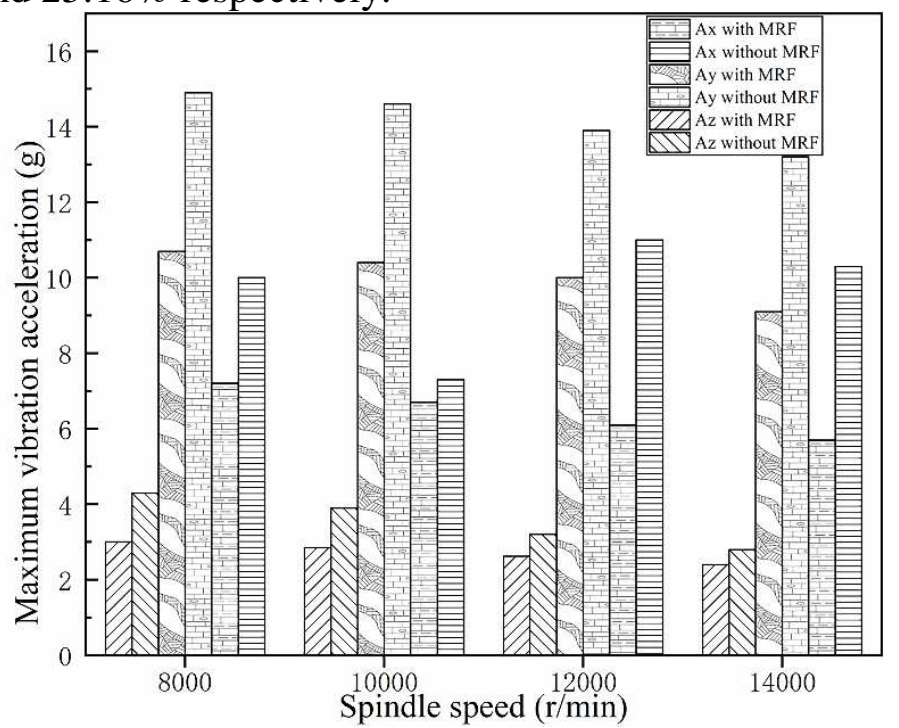

Fig. 11. Influence of spindle speed on vibration acceleration.

(2). Influence of depth of cut on workpiece vibration

Fig. 12 shows the maximum vibration acceleration in $\mathrm{Ax}$, Ay and $\mathrm{Az}$ directions with or without MRF clamping workpieces and cutting depths of $0.1 \mathrm{~mm}, 0.2 \mathrm{~mm}, 0.3$ $\mathrm{mm}$ and $0.4 \mathrm{~mm}$ respectively. It is found from the figure that the vibration acceleration increases obviously as the cutting depth increases, which indicates that the cutting depth is one of the main factors affecting the vibration of the part. The vibration acceleration with MRF clamping mode is less than that without MRF clamping, and Az, Ay and Ax decrease by $17.66 \%, 23.12 \%$ and $18.91 \%$ respectively.

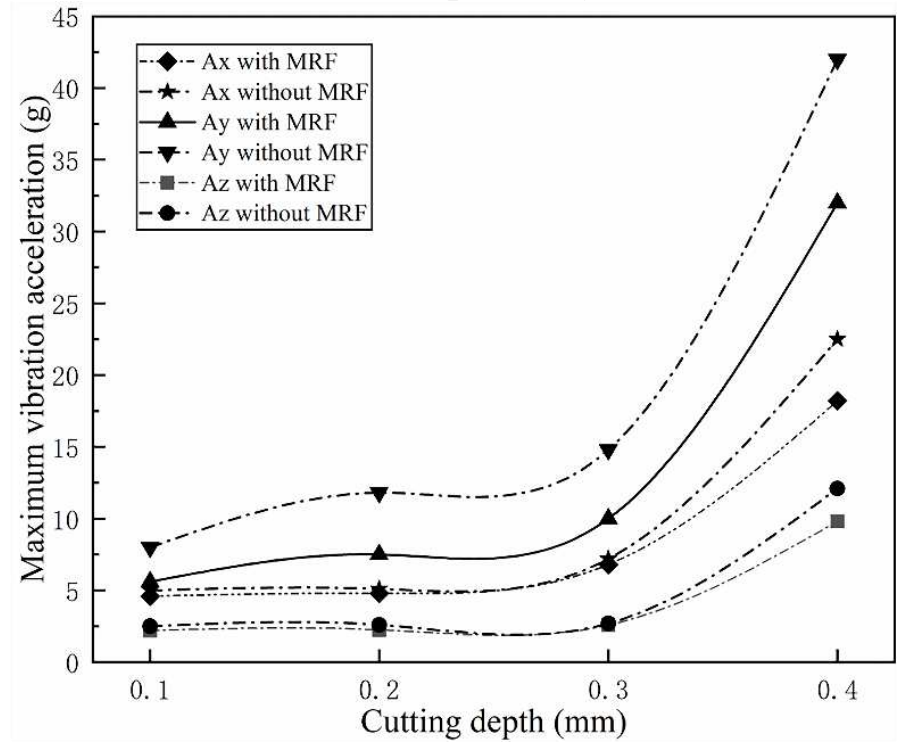

Fig. 12. Effect of cutting depth on vibration acceleration.

(3). Influence of feed speed on workpiece vibration

In numerical control machining, the feed rate is also one of the important process parameters to be considered. As shown in Fig. 13, the maximum vibration acceleration 
in Ax, Ay and Az directions is shown when the feed rates are $300(\mathrm{~mm} / \mathrm{min}), 400$ $(\mathrm{mm} / \mathrm{min}), 500(\mathrm{~mm} / \mathrm{min})$ and $600(\mathrm{~mm} / \mathrm{min})$ respectively with or without MRF clamping mode. As can be seen from Figure 11, with the increase of the feed rate, the vibration acceleration of the workpiece will also increase significantly, indicating that the feed rate is also one of the relationship factors affecting the cutting force. When the feed rates are $300 \mathrm{~mm} / \mathrm{min}$ and $400 \mathrm{~mm} / \mathrm{min}$, the vibration acceleration changes little, while the cutting force increases greatly when the feed rates are $400 \mathrm{~mm} / \mathrm{min}$ to 500 $\mathrm{mm} / \mathrm{min}$. The cutting force with MRF clamping mode is less than that without MRF clamping, and Az, Ay and Ax decrease by 12.03\%, 15.78\% and 14.38\% respectively.

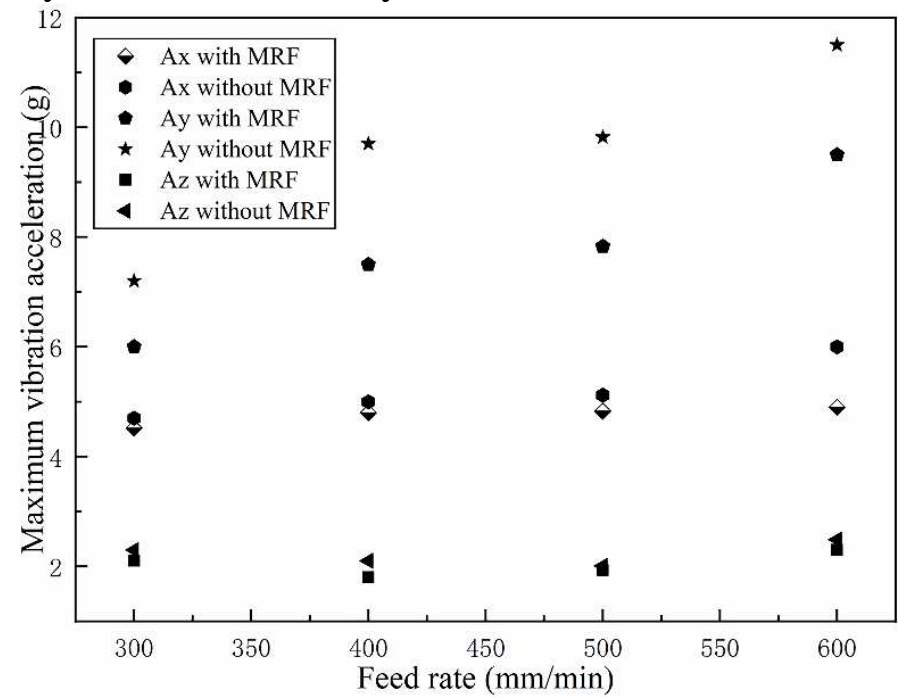

Fig. 13. Effect of feed speed on vibration acceleration.

Based on the analysis of milling results with single process parameter, no matter how the milling parameters change, the vibration acceleration Ay in Y direction (groove width direction) is always greater than that in $\mathrm{X}$ direction (feed direction), which shows that the impact force on milling cutter in groove width direction is greater than that in feed direction, so the groove width is obviously affected by cutting vibration. This is due to the constraint of the feed component force, the load borne by the milling cutter in the $\mathrm{X}$ direction is much more stable than that in the $\mathrm{Y}$ direction, so the vibration acceleration in the $\mathrm{X}$ direction is less than that in the $\mathrm{Y}$ direction. The $\mathrm{Z}$ direction is the spindle direction of the machine tool, with strong stiffness, and the cutting vibration has little influence in this direction.

\subsection{Analysis of milling test results of magnetorheological flexible}

\section{fixture}

(1). Coaxiality test of the workpiece

The coaxiality and roundness of thin-walled parts are separately tested by a threecoordinate measuring instrument (PMM-C 8.10.6) and cylindricity meter (Talyrond 565). The measurements are shown in Fig. 14 and Fig. 15. The results are as follows: Table 4. The coaxiality value of the workpiece clamped by mechanical/magnetorheological composite is smaller than that of the workpiece clamped by mechanical, with a decrease of $13.85 \%$, the cylindricity of the cylinder with a diameter of $24 \mathrm{~mm}$ is reduced by $36.73 \%$, and the cylindricity of the cylinder with a diameter of $30 \mathrm{~mm}$ is reduced by $28.29 \%$. It can be seen that mechanical/magnetorheological composite clamping small pot is obviously better than mechanical clamping. 


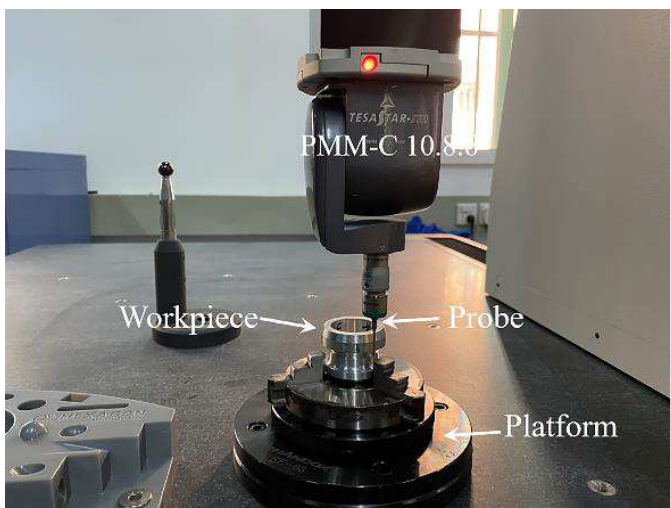

Fig. 14 Coaxiality test

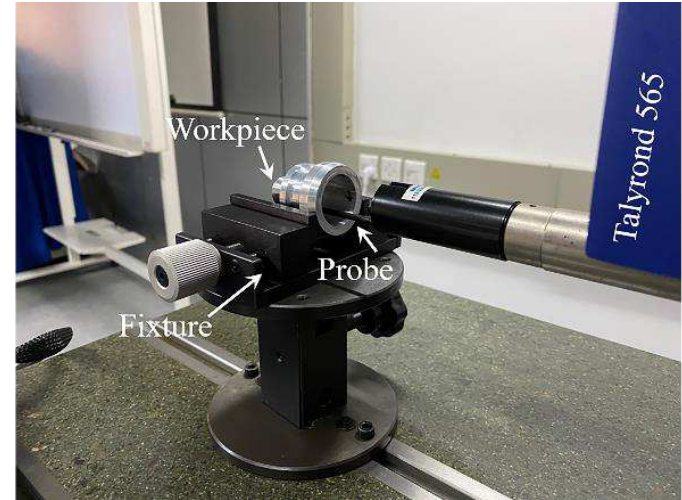

Fig. 15 Roughness measurement

Table 4. Coaxiality of thin-wall parts with circular groove

\begin{tabular}{cccc}
\hline Clamping methods & Coaxiality & $\begin{array}{c}\text { Diameter 24 mm } \\
\text { cylindricity }\end{array}$ & $\begin{array}{c}\text { Diameter 30 mm } \\
\text { cylindricity }\end{array}$ \\
\hline Mechanical clamping & 0.013 & 0.0076 & 0.094 \\
Momposite clamping & 0.0112 & 0.0047 & 0.0674 \\
\hline
\end{tabular}

(2). Roughness measurement of thin-walled parts

The roughness of irregular thin-walled parts is tested by TAYLOR HOBSON roughness profiler, as shown in Fig. 15. The roughness of thin-walled parts processed by magnetorheological flexible fixture is measured, and the measurement results are shown in Table 5. Among them, the first group of test points are cylinders with a diameter of $24 \mathrm{~mm}$ at the bottom of the workpiece, the second group is cylinders with a wall thickness of $1.5 \mathrm{~mm}$ at the thinnest part of the workpiece, the third group is cylinders with a diameter of $39 \mathrm{~mm}$ at the upper part of the workpiece, and the fourth group is the inner wall roughness of holes with a diameter of $27 \mathrm{~mm}$.

Table 5. Test results of workpiece roughness

\begin{tabular}{ccccc}
\hline Test point & Group 1 & Group 2 & Group 3 & Group 4 \\
\hline $\operatorname{Ra}(\mu \mathrm{m})$ & 0.26 & 0.30 & 0.25 & 0.73 \\
$\operatorname{Rz}(\mu \mathrm{m})$ & 1.18 & 1.27 & 1.31 & 3.05 \\
$\operatorname{Rq}(\mu \mathrm{m})$ & 0.32 & 0.36 & 0.34 & 0.96 \\
\hline
\end{tabular}

From Table 5, it is shown that the roughness of the outer surface of the part is related to the wall thickness of the workpiece. The roughness is the largest where the wall thickness is the smallest, and the roughness value of the inner surface is larger than that of the outer surface. This is because the hole is the last machining process, the removal rate of the workpiece is large, and the stiffness is small.

Table 6. Comparison of workpiece roughness in different clamping methods

\begin{tabular}{cccc}
\hline Test point 2 & $\begin{array}{c}\text { Mechanical } \\
\text { clamping }\end{array}$ & $\begin{array}{c}\text { Magnetorheological } \\
\text { clamping }\end{array}$ & $\begin{array}{c}\text { Mechanical/Magnetorheological } \\
\text { clamping }\end{array}$ \\
\hline $\operatorname{Ra}(\mu \mathrm{m})$ & 1.33 & 0.65 & 0.30 \\
$\operatorname{Rz}(\mu \mathrm{m})$ & 6.47 & 3.25 & 1.27 \\
$\operatorname{Rq}(\mu \mathrm{m})$ & 1.58 & 0.76 & 0.36 \\
\hline
\end{tabular}


As can be seen from Table 6, the roughness values $\mathrm{Ra}, \mathrm{Rz}$ and $\mathrm{Rq}$ of the mechanical/magnetorheological composite clamping method in milling thin-walled parts are $77.44 \%, 80.47 \%$ and $77.21 \%$ lower than those of mechanical clamping respectively. Compared with magnetorheological clamping, it is reduced by $53.84 \%$, $60.92 \%$ and $52.63 \%$ respectively.

\section{Conclusion}

In this paper, the vibration and weak stiffness in the machining process of workpiece are studied. Compared with the clamping effect of traditional clamping tools, it is found that magnetorheological flexible clamping tools can obviously improve the surface machining quality of parts. Considering single process parameter milling, optimization suggestions are put forward for the machining process. The conclusions are exhibited as follows:

1. Compared with the traditional fixture clamping, the milling vibration acceleration Az, Ay and Ax are reduced by 10.78\%, 26.87\% and 25.16\% at most, respectively, and the vibration of the workpiece can be reduced by appropriately increasing the rotational speed; As the cutting depth increases, the vibration increases. The vibration acceleration with MRF clamping mode is less than that without MRF clamping, and Az, Ay and Ax decrease by $17.66 \%, 23.12 \%$ and $18.91 \%$ respectively. With the increase of feed speed and vibration, the cutting force with MRF clamping mode is less than that without MRF clamping, and Az, Ay and Ax decrease by $12.03 \%$, $15.78 \%$ and $14.38 \%$ respectively.

2. The coaxiality value of mechanical/magnetorheological composite clamping workpiece is less than that of mechanical clamping, with a decrease of $13.85 \%$, the cylindricity of $24 \mathrm{~mm}$ diameter cylinder is reduced by $36.73 \%$, and the cylindricity of $30 \mathrm{~mm}$ diameter cylinder is reduced by $28.29 \%$. The roughness values $\mathrm{Ra}, \mathrm{Rz}$ and $\mathrm{Rq}$ are $77.44 \%, 80.47 \%$ and $77.21 \%$ lower than those of mechanical clamping respectively, and $53.84 \%, 60.92 \%$ and $52.63 \%$ lower than those of magnetorheological clamping respectively.

\section{Author contribution}

Yong Zhang and Shan Gao are the main authors and contribute in drafting the article, and Guokuan Zhao and Ning Yang contribute in editing the article and act as supervisor for the Xiaohui Jiang and Xiao Liu.

\section{Funding}

This project is supported by the Shanghai Science and Technology Commission (Grant No. 20ZR1438000) and Innovation Funding of Shanghai Aerospace Science and Technology (Grant No. SAST2019-065).

\section{Availability of data and materials}

Not applicable.

\section{Declarations}

\section{Ethics approval}

The authors declare compliance with ethical standards.

\section{Consent to participate}

The authors consent to participate. 


\section{Consent for publication}

The authors consent to publish.

\section{Conflict of interest}

The authors declare no competing interests.

\section{References}

[1] Shi JH, Song QH, Liu ZQ, Ai X (2017) A novel stability prediction approach for thin-walled component milling considering material removing process. Chinese $\mathrm{J}$ Aeronanut 30(5): 1789-1798.

[2] Bakker OJ, Papastathis TN, Popov AA, Ratchev SM (2013) Active fixturing: literature review and future research directions. Int J Prod Res 51(11): 3171-3190.

[3] Selvakumar S, Arulshri KP, Padmanaban KP, Sasilkumar KSK (2013) Design and optimization of machining fixture layout using ANN and DOE. Int $\mathrm{J}$ Adv Manuf Technol 65(9-12): 1573-1586.

[4] Li YG, Liu CQ, Gao JX, Shen WM (2015) An integrated feature-based dynamic control system for on-line machining, inspection and monitoring. Integr Comput-Aid $\mathrm{E}$ 22(2): 187-200.

[5] Mohring HC, Wiederkehr P (2016) Intelligent Fixtures for High Performance Machining. Procedia CIRP 46: 383-390.

[6] Wang ZJ, Chen WY, Zhang YD, Chen ZT, Liu Q (2005) Study on the Machining Distortion of Thin-walled Part Caused by Redistribution of Residual Stress. Chinese J Aeronanut 18(2):175-9.

[7] Jiang XH, Kong XJ, Zhang ZY, Wu ZP, Ding ZS, Guo MX (2020) Modeling the effects of Undeformed Chip Volume(UCV)on residual stresses during the milling of curved thin-walled parts. Int J Mech Sci 167.

[8] Wu BH, Yan X, Luo M, Gao G (2013) Cutting force prediction for circular end milling process. Chinese J Aeronanut 26(4): 1057-1063.

[9] Fekrmandi H, Unal M, Baghalian A, Tashakori S, Oyola K, Alsenawi A, Tansel IN (2016) A non-contact method for part-based process performance monitoring in end milling operations. Int J Adv Manuf Technol 83(1-4): 13-20.

[10] Niu JB, Ding Y, Zhu LM, Ding H (2016) Stability Analysis of Milling Processes With Periodic Spindle Speed Variation Via the Variable-Step Numerical Integration Method. J. Manuf. Sci. E-T. Asme 138(11).

[11] Ding Y, Niu JB, Zhu LM, Ding H (2016) Numerical Integration Method for Stability Analysis of Milling with Variable Spindle Speeds. J Vib Acoust 138(1).

[12] Seguy S, Insperger T, Arnaud L, Dessein G, Peigne G (2010) On the stability of high-speed milling with spindle speed variation. Int J Adv Manuf Technol 48(9-12): 883-895.

[13] Campa FJ, deLacalle LNL, Celaya A (2011) Chatter avoidance in the milling of thin floors with bull-nose end mills: Model and stability diagrams. Int J Mach Tool Manuf 51(1): 43-53.

[14] Ismail F, Ziaei R (2002) Chatter suppression in five-axis machining of flexible parts. Int J Mach Tool Manuf 42(1): 115-122. 
[15] Ozturk E, Tunc L T, Budak E (2009) Investigation of lead and tilt angle effects in 5-axis ball-end milling processes. Int J Mach Tool Manuf 49(14): 1053-1062.

[16] Ozturk E, Budak E (2010) Dynamics and Stability of Five-Axis Ball-End Milling. J Manu Sci Eng 132(2): 237-247.

[17] Singh M, Singh AK (2019) Performance investigation of magnetorheological finishing of rolls surface in cold rolling process. J Manuf Process 41: 315-329.

[18] Yadav RD, Singh AK, Arora K (2020) Parametric analysis of magnetorheological finishing process for improved performance of gear profile. J Manuf Process 57: 254267.

[19] Tang X, Zhang X, Tao R (1999) Flexible fixture device with magneto-rheological fluids. J. Intel. Mat. Syst. Str 10(9): 690-694.

[20] Aydar G, Wang XJ, Gordaninejad F (2010) A novel two-way-controllable magneto-rheological fluid damper. Smart. Mater. Struct 19(6).

[21] Mughni MJ, Zeinali M, Mazlan SA, Zamzuri H, Rahman MAA (2015) Experiments and modeling of a new magnetorheological cell under combination of flow and shear-flow modes. J. Non-Newton. Fluid 215: 70-79.

[22] Imadduddin F, Mazlan SA, Zamzuri H (2013) A design and modelling review of rotary magnetorheological damper. Mater Design 51: 575-591.

[23] Jiang XH, Zhang Y, Lu WW, Gao S, Liu L, Liu X (2020) Characteristics of shear stress based on magnetorheological fluid flexible fixture during milling of the thinwalled part. Int. J. Adv. Manuf. Technol 108(7-8): 2607-2619.

[24] Kim K, Chen ZB, Yu D, Rim C (2016) Design and experiments of a novel magnetorheological damper featuring bifold flow mode. Smart. Mater. Struct 25(7).

[25] Jiang XH, Zhao GK, Lu WW (2020) Vibration suppression of complex thin-walled workpiece based on magnetorheological fixture. Int. J. Adv. Manuf. Technol 106(3-4): 1043-1055.

[26] Ma JJ, Zhang DH, Wu BH, Luo M, Chen B (2016) Vibration suppression of thinwalled workpiece machining considering external damping properties based on magnetorheological fluids flexible fixture. Chinese. J. Aeronaut 29(4): 1074-1083.

[27] Zhou ZH, Zhang CY, Xie Y, Luo M, Shao XY (2014) Research on Modeling of Cutting Force on CNC Lathe Based on Orthogonal Experiment. Adv. Mater 912-914: 748-752. 


\section{Figures}

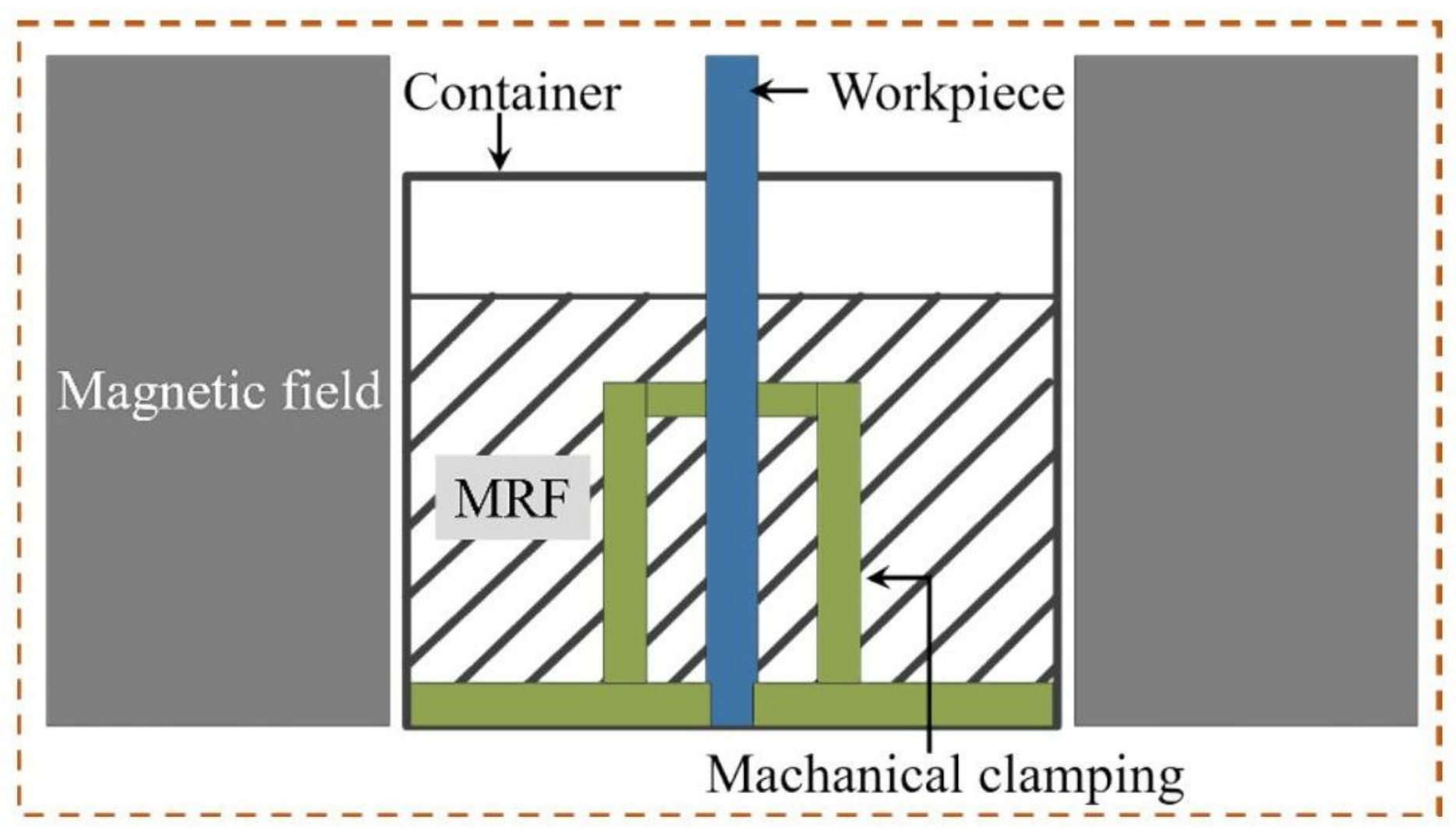

Figure 1

The schematic diagram of magnetorheological flexible fixture.
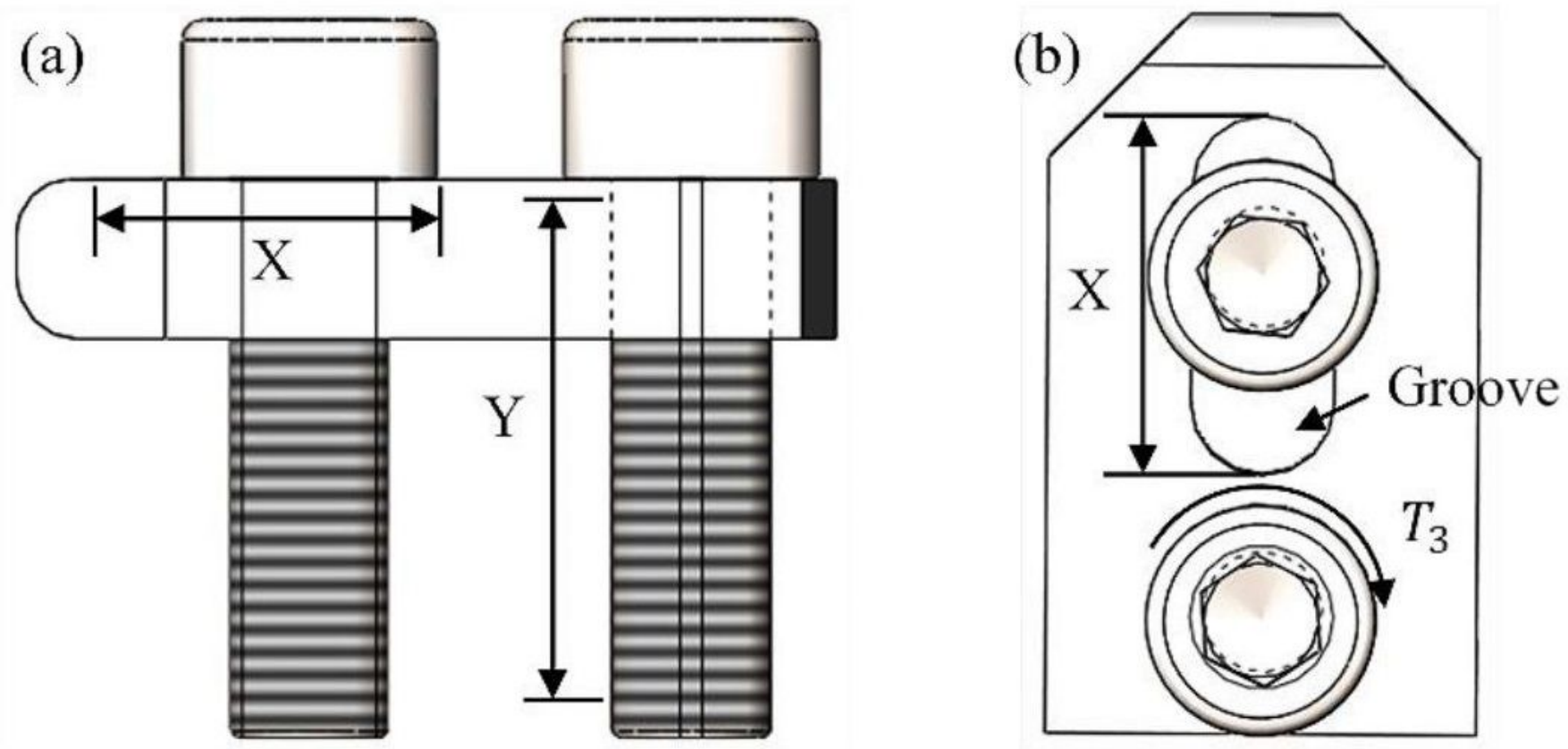

Figure 2 
Stress of bolts and V-shaped blocks when fixing thin-walled parts. (a) top view; (b) torque of the bolt.

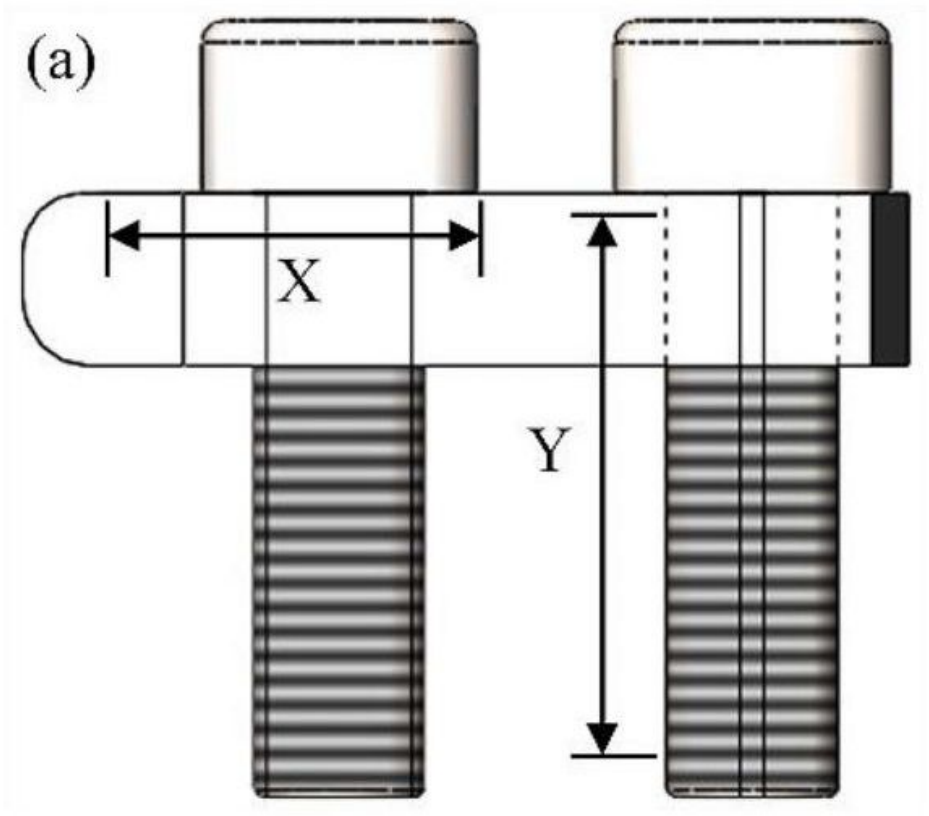

(b)

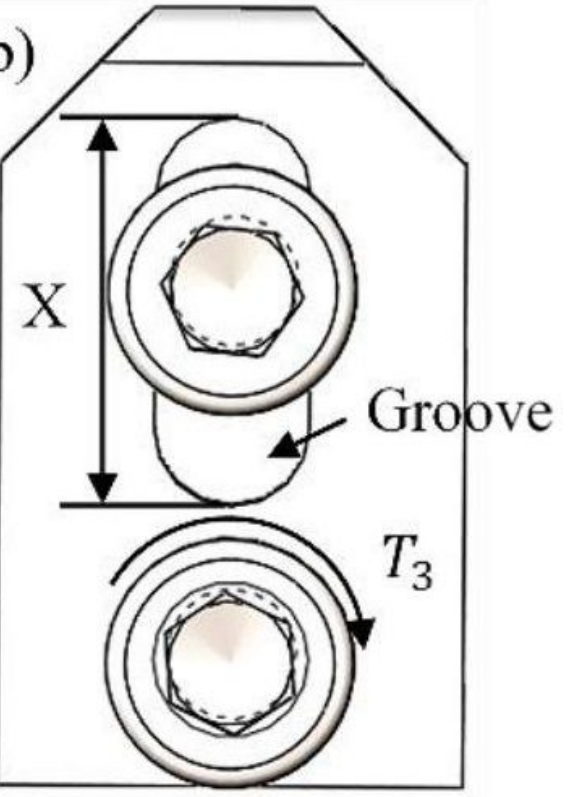

Figure 3

Fixing of pressing plate. (a) front view; (b) top view.
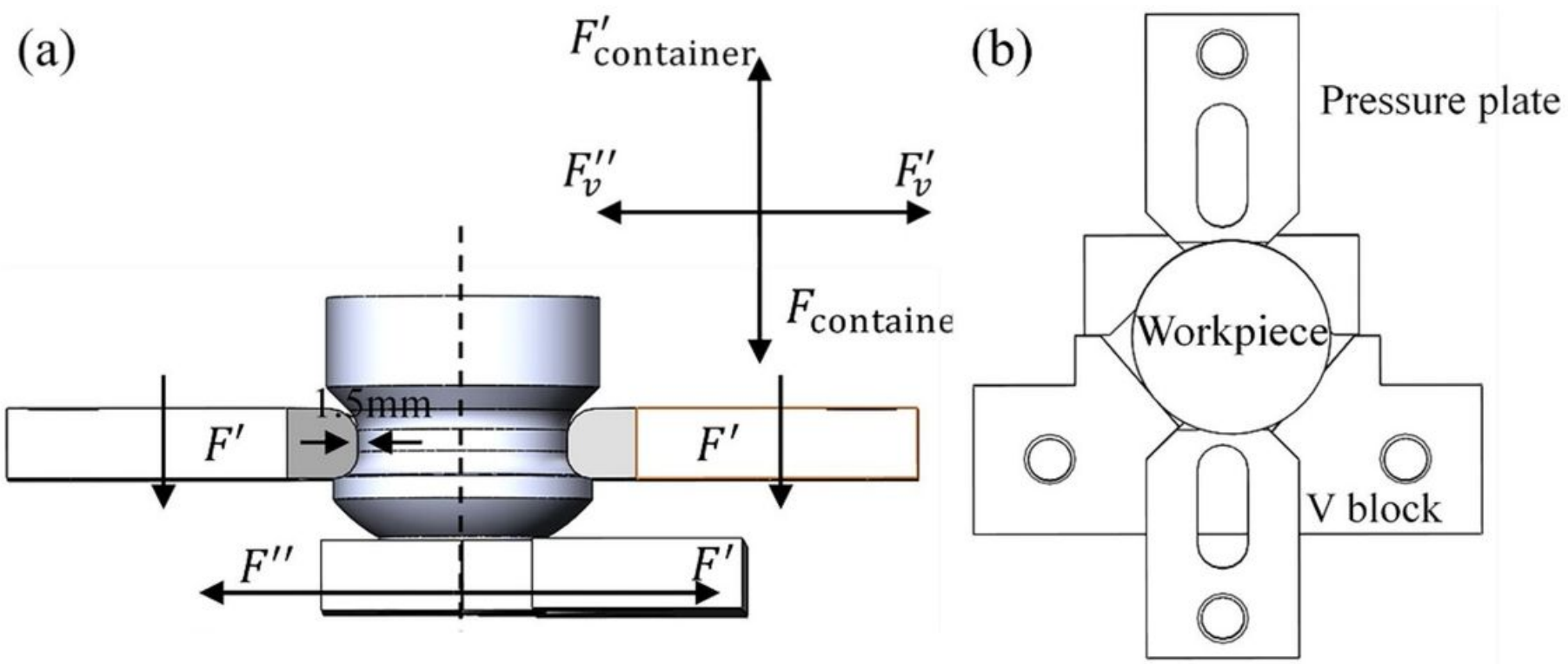

Figure 4

Mechanical clamping and fixing. (a) front view; (b) top view. 


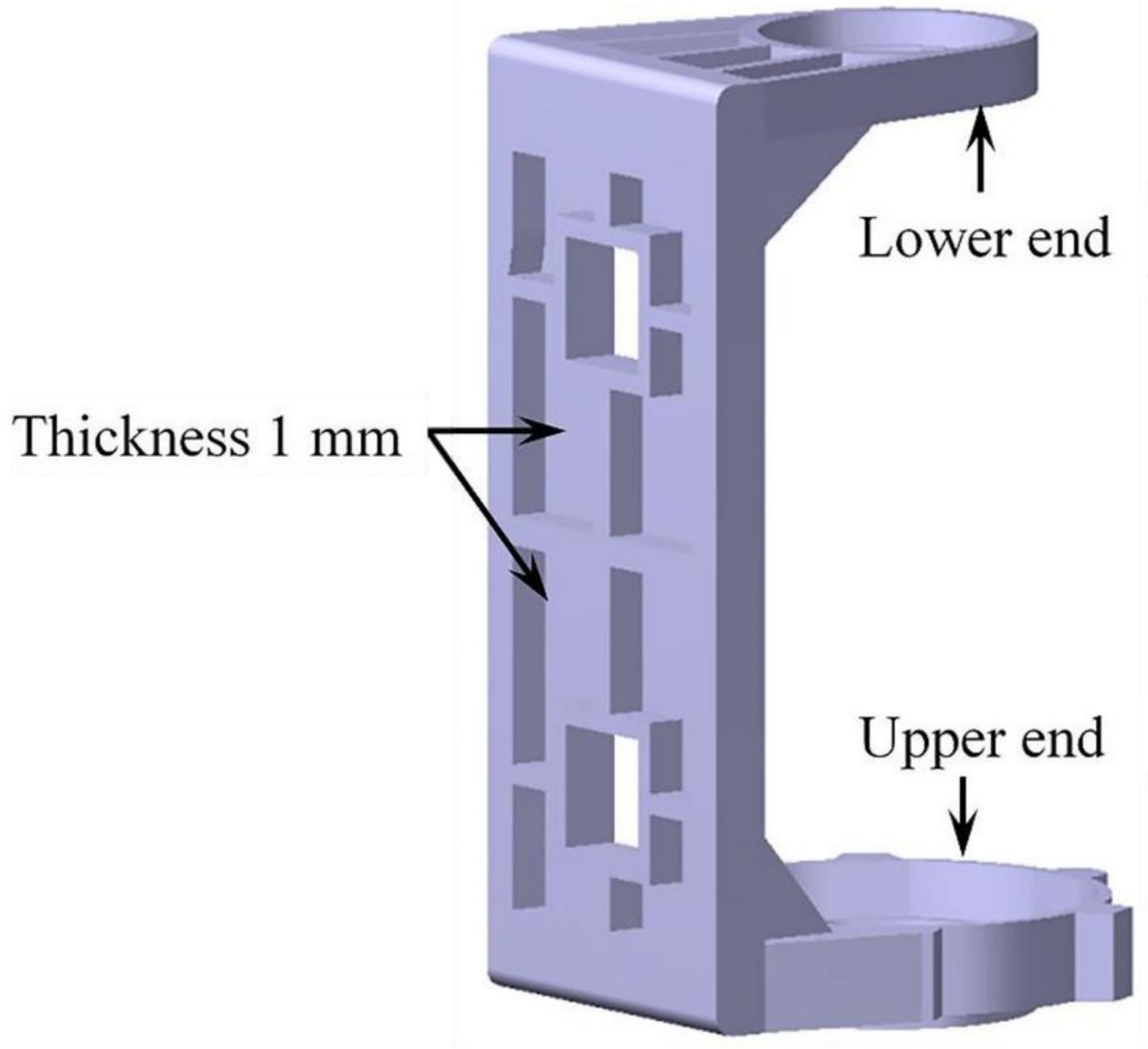

Figure 5

Diagram of frame type aluminum alloy thin-walled part. 


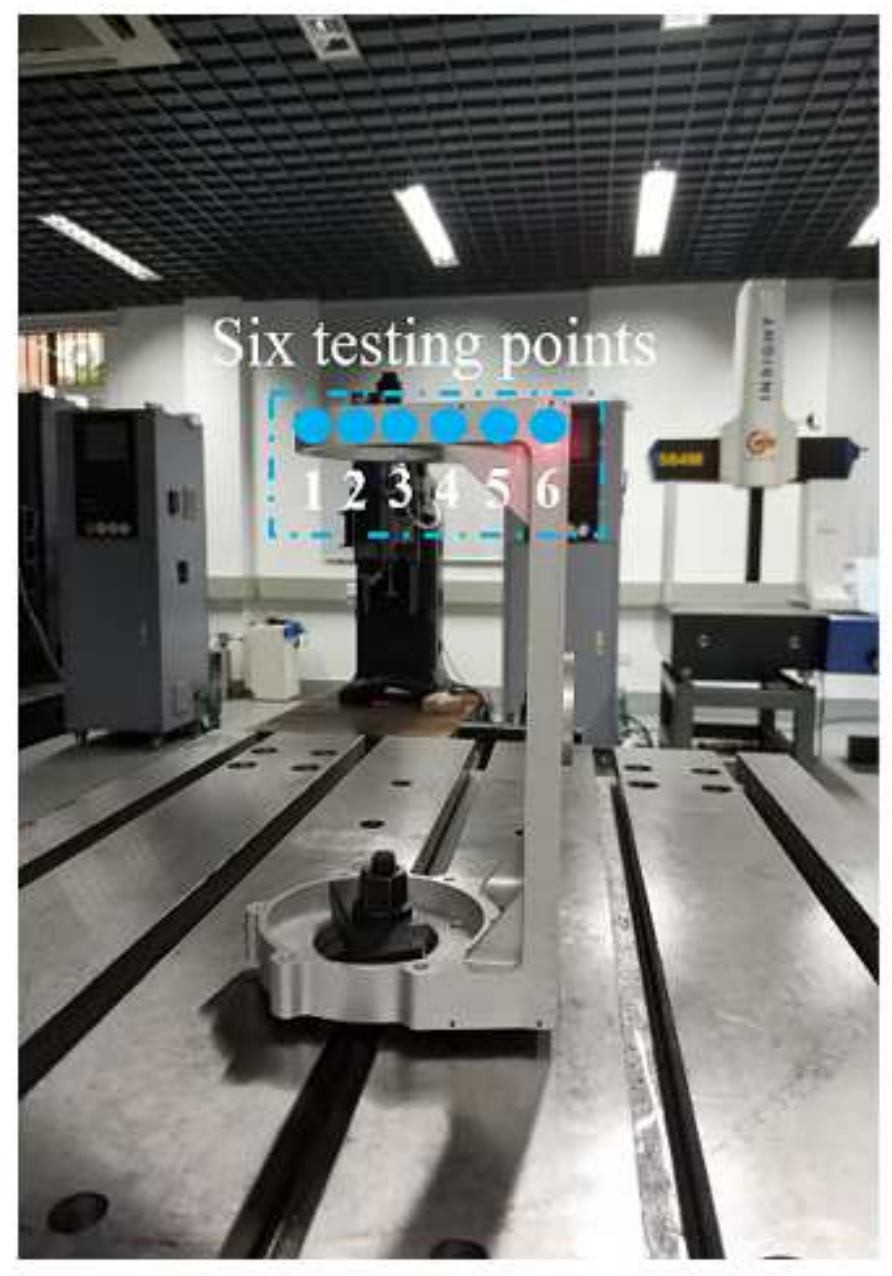

Figure 6

Stiffness test of thin-walled parts 


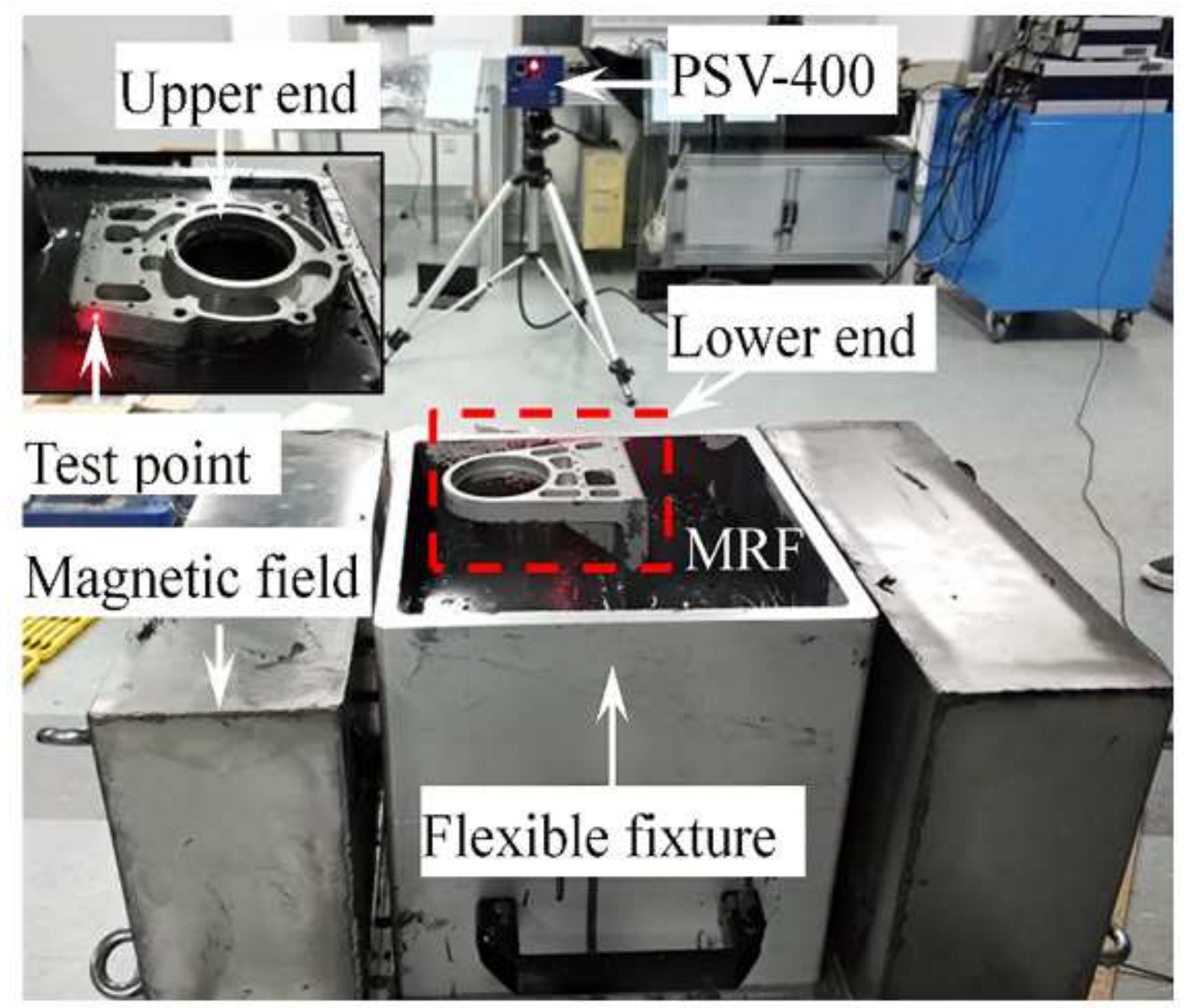

Figure 7

Stiffness test of flexible fixture.
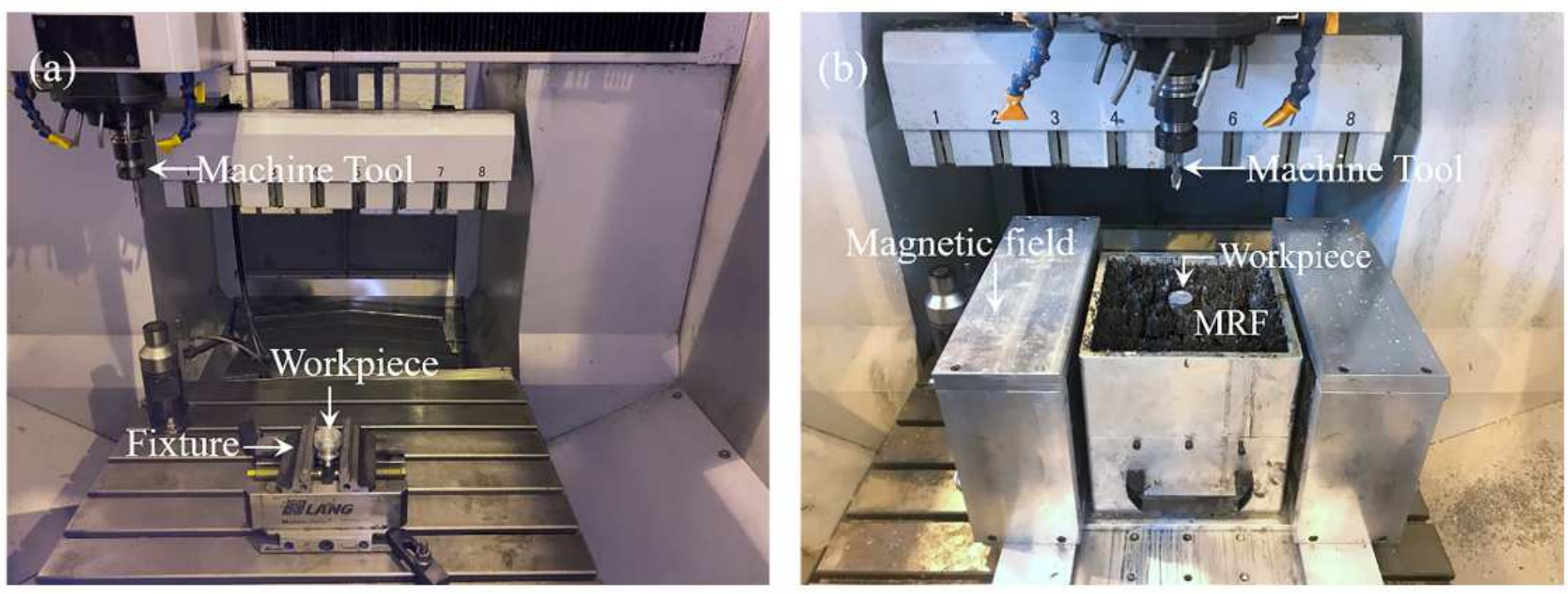

Figure 8

Experimental machining. (a) mechanical clamping; (b) magnetorheological clamping. 


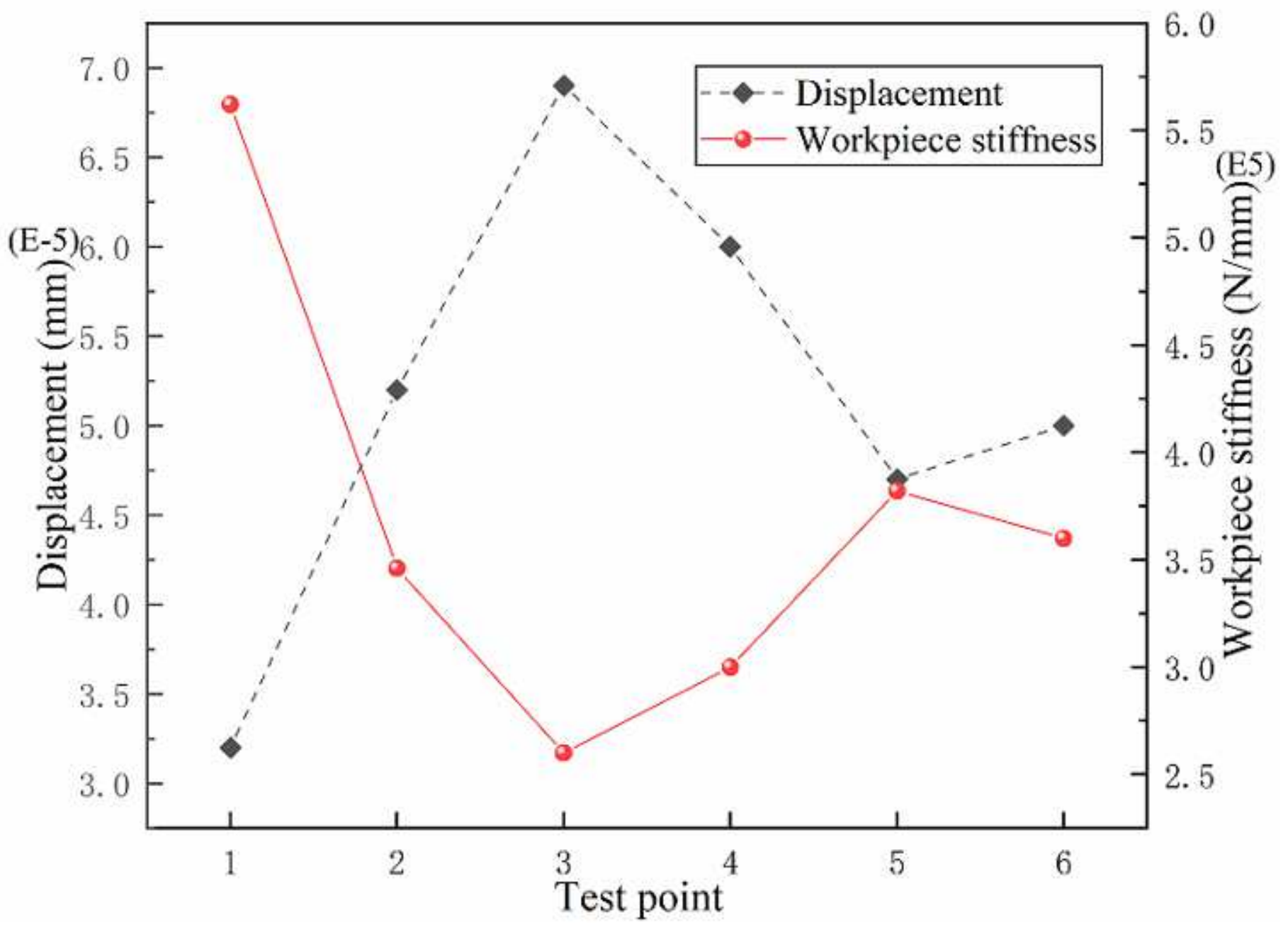

Figure 9

Test results of workpiece point stiffness. 


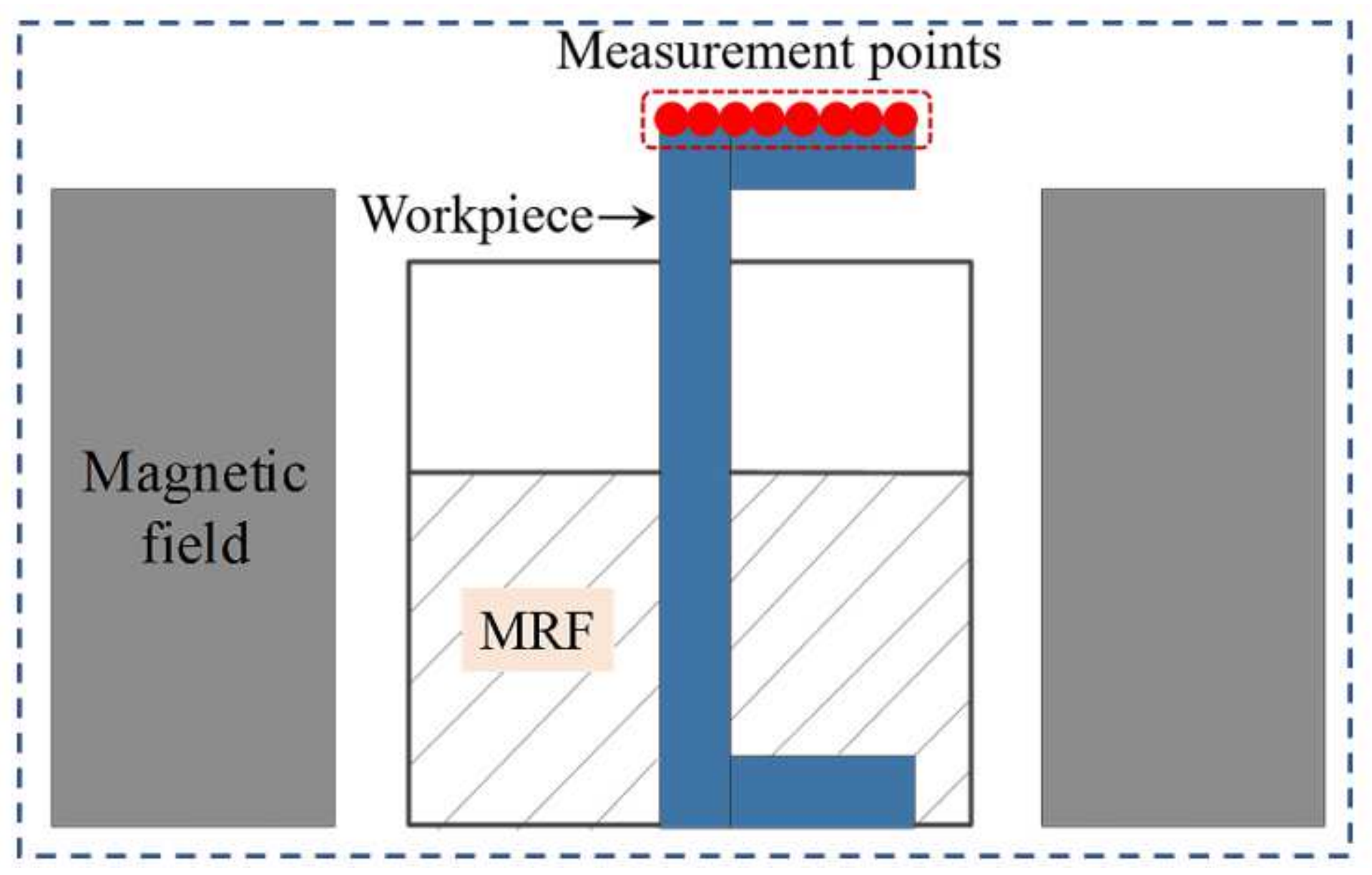

Figure 10

Diagram of test points positions. 


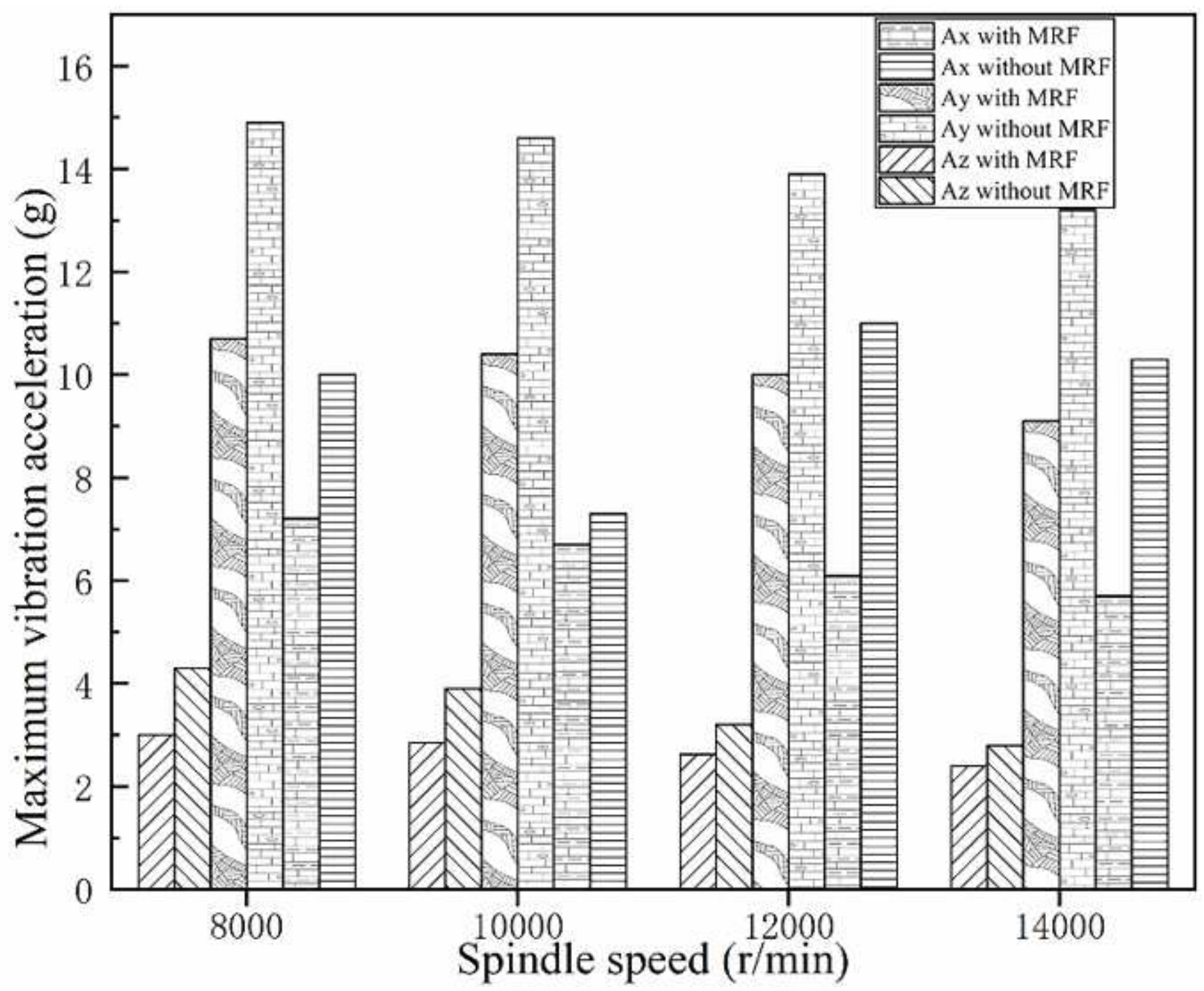

Figure 11

Influence of spindle speed on vibration acceleration. 


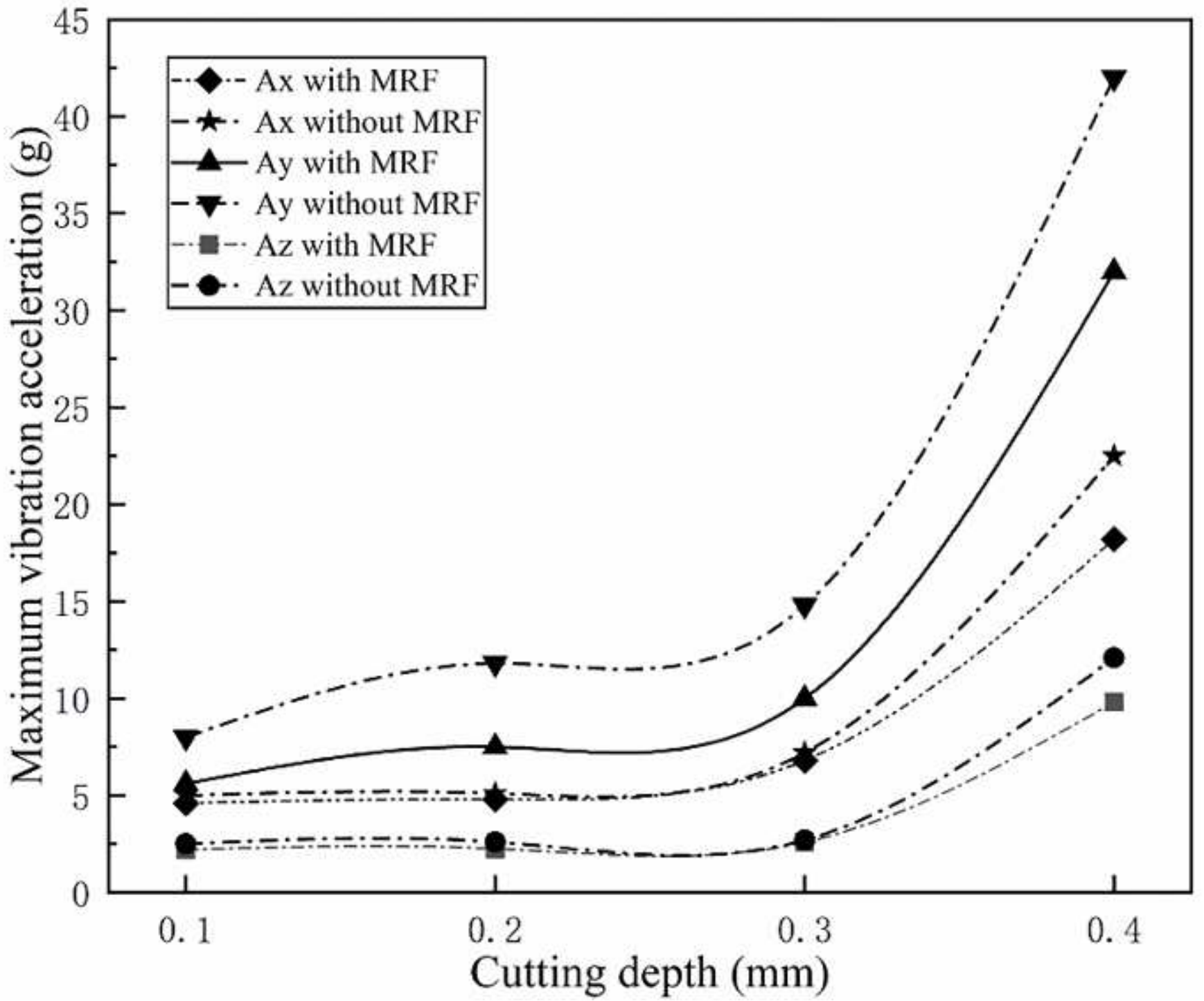

Figure 12

Effect of cutting depth on vibration acceleration. 


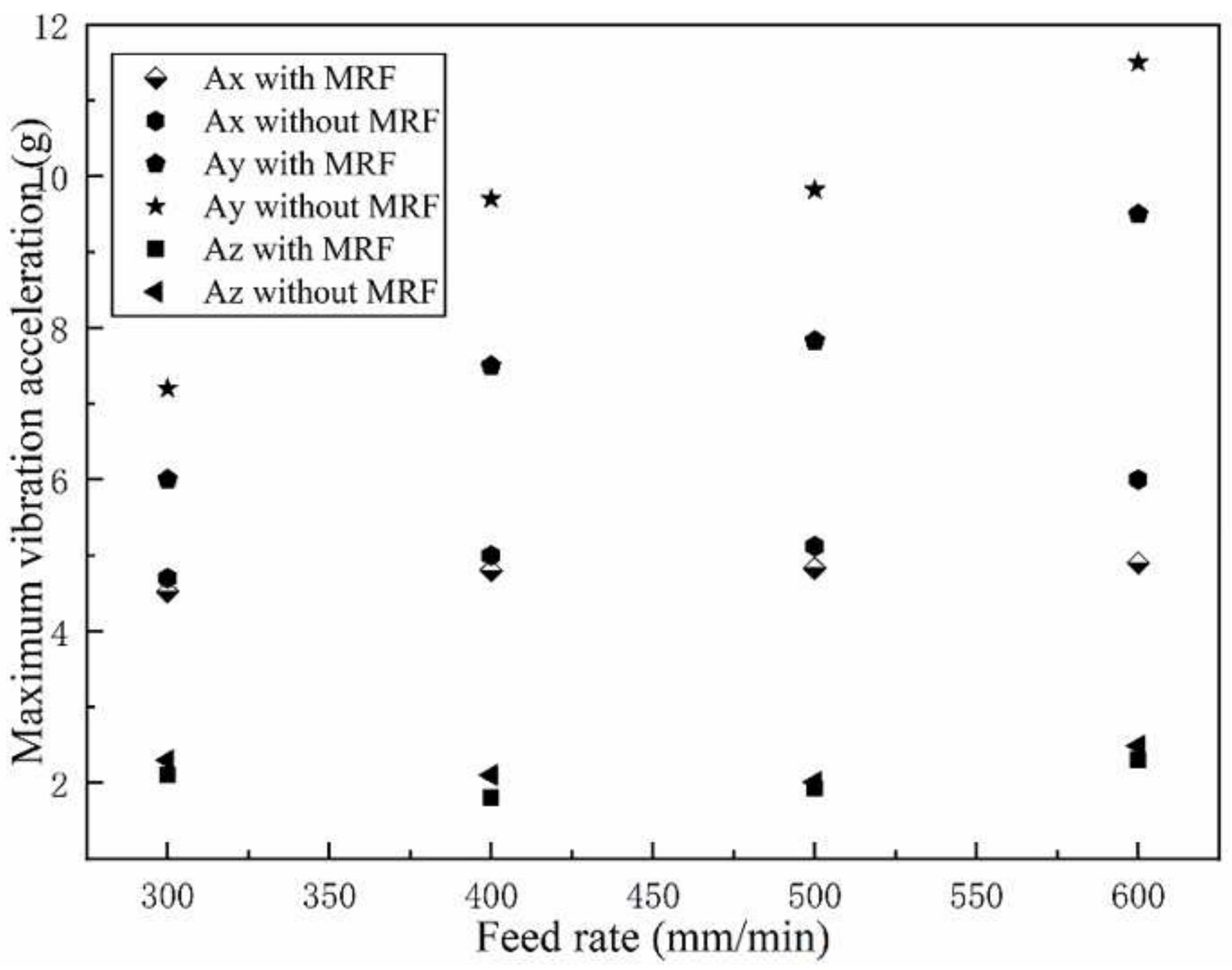

Figure 13

Effect of feed speed on vibration acceleration. 


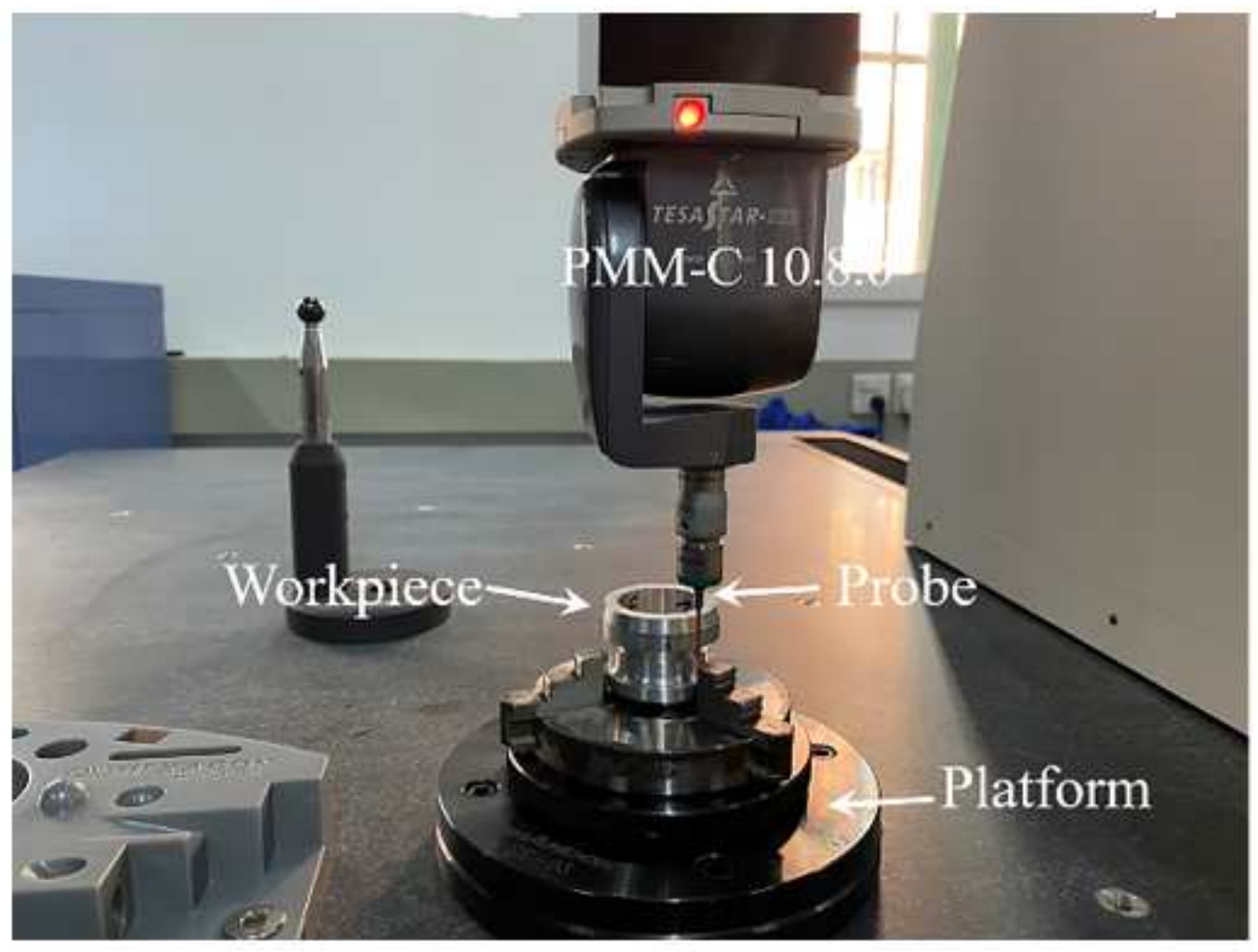

Figure 14

Coaxiality test

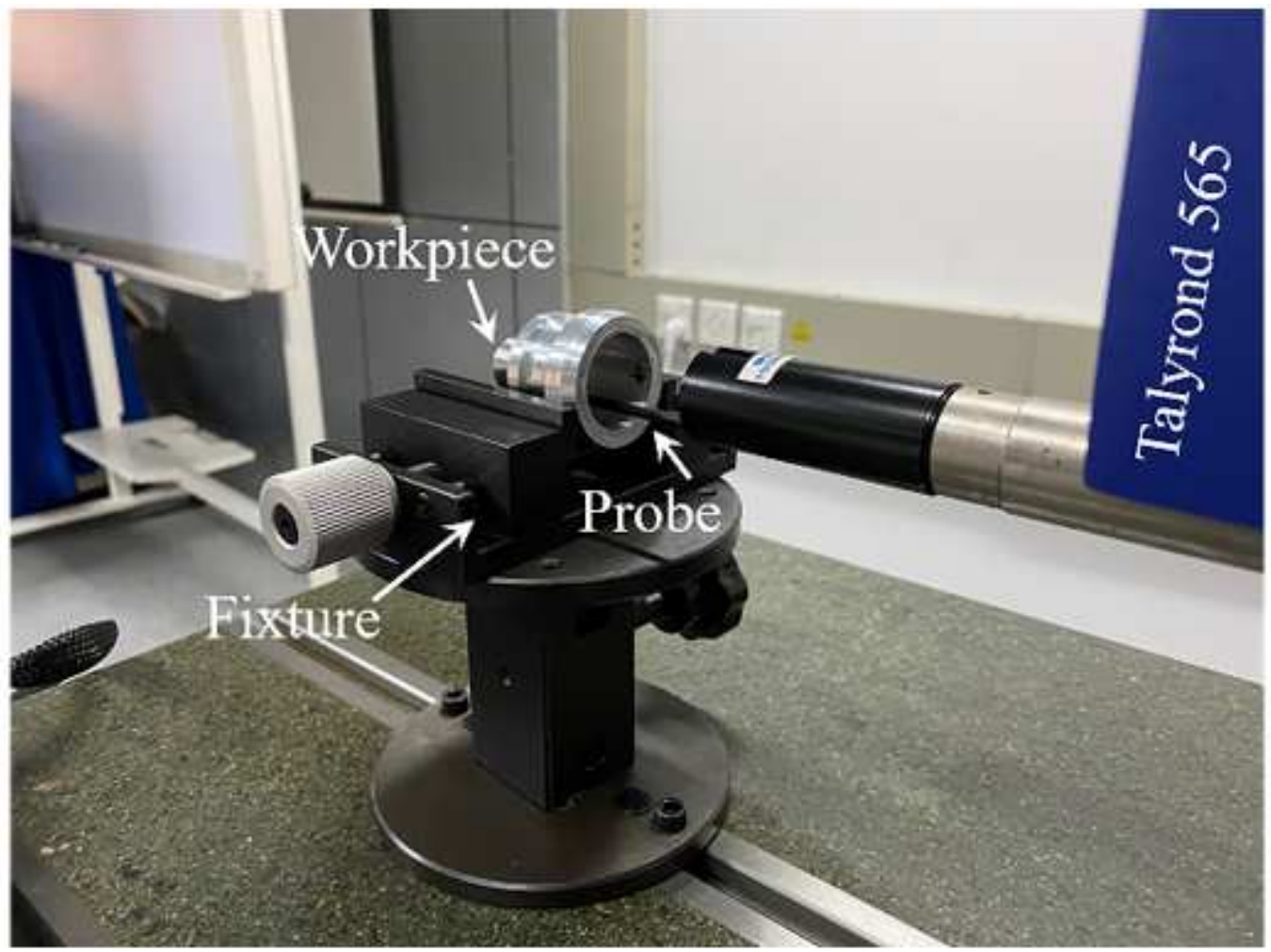

Figure 15 